\title{
Neurotrophic Factors and Receptors in the Immature and Adult Spinal Cord after Mechanical Injury or Kainic Acid
}

\author{
Johan Widenfalk, Karin Lundströmer, Marie Jubran, Stefan Brené, and Lars Olson \\ Department of Neuroscience, Karolinska Institute, S-171 77 Stockholm, Sweden
}

Delivery of neurotrophic factors to the injured spinal cord has been shown to stimulate neuronal survival and regeneration. This indicates that a lack of sufficient trophic support is one factor contributing to the absence of spontaneous regeneration in the mammalian spinal cord. Regulation of the expression of neurotrophic factors and receptors after spinal cord injury has not been studied in detail. We investigated levels of mRNAencoding neurotrophins, glial cell line-derived neurotrophic factor (GDNF) family members and related receptors, ciliary neurotrophic factor (CNTF), and c-fos in normal and injured spinal cord. Injuries in adult rats included weight-drop, transection, and excitotoxic kainic acid delivery; in newborn rats, partial transection was performed. The regulation of expression patterns in the adult spinal cord was compared with that in the PNS and the neonate spinal cord. After mechanical injury of the adult rat spinal cord, upregulations of NGF and GDNF mRNA occurred in meningeal cells adjacent to the lesion. BDNF and p75 mRNA increased in neurons, GDNF mRNA increased in astrocytes close to the lesion, and GFR $\alpha-1$ and truncated TrkB
mRNA increased in astrocytes of degenerating white matter. The relatively limited upregulation of neurotrophic factors in the spinal cord contrasted with the response of affected nerve roots, in which marked increases of NGF and GDNF mRNA levels were observed in Schwann cells. The difference between the ability of the PNS and CNS to provide trophic support correlates with their different abilities to regenerate. Kainic acid delivery led to only weak upregulations of BDNF and CNTF mRNA. Compared with several brain regions, the overall response of the spinal cord tissue to kainic acid was weak. The relative sparseness of upregulations of endogenous neurotrophic factors after injury strengthens the hypothesis that lack of regeneration in the spinal cord is attributable at least partly to lack of trophic support.

Key words: rat; GFR $\alpha$; NGF; BDNF; NT3; NT4; GDNF; NTN; CNTF; PSP; TrkA; TrkB; truncated TrkB; TrkC; p75; in situ hybridization; spinal cord injury; kainic acid; weight-drop; motoneuron
The lack of regenerative properties of the mammalian CNS is probably attributable to a combination of factors, such as the inhibitory character of glial scars and CNS white matter (Hoke and Silver, 1996; Chen et al., 2000) and lack of trophic support (Skene, 1989; Doster et al., 1991; Schnell, 1994; Tetzlaff et al., 1994; Fournier and McKerracher, 1997). Neurotrophic factors, including members of the NGF and GDNF families, are potent endogenous stimulators of neuron survival and nerve fiber growth. In addition, they have been reported to elicit beneficial effects when delivered after spinal cord injury (SCI) (Schnell, 1994; Grill et al., 1997; Kobayashi et al., 1997; Menei et al., 1998; Liu et al., 1999). However, the expression levels of mRNAencoding neurotrophic factors and their receptors after SCI have not been thoroughly studied previously. Therefore, in the present study we have characterized the expression patterns of mRNAencoding neurotrophic factors in the NGF and GDNF families and related receptors, focusing on normal spinal cord and regulations of mRNA levels in response to injury. These investigations should help clarify whether there is a lack of trophic support after

\footnotetext{
Received Sept. 1, 2000; revised Feb. 5, 2001; accepted Feb. 10, 2001.

This work was supported by the Swedish Medical Research Council (14X-03185), AMF, AFA, Petrus och Augusta Hedlunds stiftelse, and the United States Public Health Service, National Institute on Drug Abuse, and SNF Grant 31-52947.97. We thank Eva Lindqvist, Karin Lundströmer, Ida Engqvist, Karin Pernold, and Susanne Almström for excellent technical assistance.

Correspondence should be addressed to Johan Widenfalk, Department of Neuroscience, Karolinska Institutet, S-171 77 Stockholm, Sweden. E-mail: johan.widenfalk@neuro.ki.se.

Copyright @ 2001 Society for Neuroscience 0270-6474/01/213457-19\$15.00/0
}

SCI and which cells, if any, are responsible for neurotrophic factor synthesis. We also address the question of whether the spinal cord differs from the PNS, where successful regeneration occurs, in terms of injury-induced mRNA patterns. Moreover we ask whether the adult spinal cord differs from the neonate spinal cord in these respects, because a degree of regeneration or rerouting, or both, is known to take place after SCI in the neonate (Bernstein and Stelzner, 1983; Bregman and Goldberger, 1983). Finally, we have used the excitotoxin kainic acid, known to induce profound upregulation of neurotrophic factors and receptors in the brain, to determine whether any of these upregulations are shared by the spinal cord.

In addition to the NGF and GDNF families and their receptors, we also investigated expression levels of ciliary neurotrophic factor (CNTF). Glial fibrillary acidic protein (GFAP), myelinassociated glycoprotein (MAG), and c-fos were used to monitor the degree of lesion and the astrocytes and oligodendrocytes.

NGF, BDNF, NT3, and NT4 constitute the NGF family of neurotrophic factors (the neurotrophins), which act through the high-affinity receptor tyrosine kinases (TrkA, TrkB, TrkC) and the low-affinity p75 receptor (Lindsay, 1994). GDNF, neurturin (NTN), persephin (PSP), and artemin (ART) constitute the GDNF family of ligands, which belongs to the TGF $\beta$ superfamily, and signal by binding to GFR $\alpha$-1-4 (Ibáñez, 1998; Baloh et al., 2000) followed by activation of the signal-transducing tyrosine kinase RET (Martin-Zanca et al., 1986; Treanor et al., 1996; Trupp et al., 1996). During development, the neurotrophic factors support survival of and neurite outgrowth from various neuron 


\begin{tabular}{|c|c|c|c|c|c|c|c|c|c|c|c|}
\hline \multirow[b]{2}{*}{ Group } & \multirow[b]{2}{*}{ Noninjured } & \multicolumn{10}{|c|}{ Time after injury/delivery } \\
\hline & & $2 \mathrm{hr}$ & $4 \mathrm{hr}$ & $6 \mathrm{hr}$ & $12 \mathrm{hr}$ & $1 \mathrm{~d}$ & $3 \mathrm{~d}$ & 1 week & $10 \mathrm{~d}$ & 6 weeks & 6 months \\
\hline \multicolumn{12}{|l|}{ Adults } \\
\hline Normal & 21 & & & & & & & & & & \\
\hline Weight-drop & & 4 & & 4 & & 6 & 4 & 8 & & 24 & 1 \\
\hline Transection & & & & & & 12 & 2 & 4 & 4 & 5 & \\
\hline Sham & & 2 & & 2 & & 1 & & & & & \\
\hline Kainic acid & & 3 & 9 & & & 6 & 3 & 3 & & & \\
\hline Ringer's solution & & 3 & 4 & & & 4 & 2 & 2 & & & \\
\hline \multicolumn{12}{|l|}{ Neonates } \\
\hline Normal & 15 & & & & & & & & & & \\
\hline Partial transection & & & & 5 & 11 & 11 & & & & & 4 \\
\hline Sham & & & & 1 & 1 & 1 & & & & & \\
\hline
\end{tabular}

populations. Limited amounts of neurotrophic factors are produced in the adult CNS, and the roles of neurotrophic factors in the adult brain and spinal cord are less well understood. They may increase neuronal survival (Tomac et al., 1995; Novikova et al., 1996), induce regeneration after injury (Schnell, 1994; Tuszynski et al., 1996; Grill et al., 1997; Kobayashi et al., 1997; Houweling et al., 1998; Menei et al., 1998; Liu et al., 1999), and be involved in synapse plasticity (McAllister et al., 1999). Neurotrophic factors have additionally been shown to prevent neurodegeneration after excitotoxic damage to the CNS (Tomac et al., 1995; Horger et al., 1998; Milbrandt et al., 1998; Rosenblad et al., 1999, 2000).

There are few reports dealing with regulation of neurotrophins or their receptors after spinal cord perturbations. Frisén and colleagues $(1992,1993)$ demonstrated upregulation of truncated TrkB mRNA in cells in the glial scar 3 weeks after longitudinal dorsal funiculus cuts. After SCI, the low-affinity receptor p75 upregulates in cells associated with blood vessels (Reynolds et al., 1991). A massive glial BDNF and NT3 expression close to the lesion shortly after SCI was reported recently (Hayashi et al., 2000). There are no previous studies of regulation of these molecules after weight-drop injury produced using the NYU impactor (Gruner, 1992). Dramatic upregulations of BDNF and NT4 mRNA in glial cells and neurons of the spinal cord after kainic acid delivery have been reported (Scarisbrick et al., 1999). The expression of GDNF family ligands and related receptors after SCI has not been studied previously.

We describe widespread expression of different neurotrophic factor receptors in the normal adult spinal cord, whereas expressions of ligands were low and spatially restricted. Upregulations of neurotrophic factors in gray and white matter of the spinal cord after injury were limited, indicating a relative lack of trophic support in the spinal cord. Strong neurotrophic factor expression was found in meningeal cells, whereas neurons and astrocytes presented only low levels. In contrast to the spinal cord glia, Schwann cells of affected nerve roots readily increased their neurotrophic factor synthesis, demonstrating a different ability of the PNS to provide trophic support. The regulation of neurotrophic factors in the spinal cord of newborn rats was almost identical to that found in adults. Kainic acid delivery led to only minor increases of neurotrophic factor levels and c-fos in the spinal cord. Brain regions of these animals exhibited more robust increases of c-fos, neurotrophic factors, and their receptors. Taken together, these results support the hypothesis that lack of regeneration in the spinal cord is attributable, at least partly, to lack of trophic support.

\section{MATERIALS AND METHODS}

Animals

A total of 154 adult female and 45 newborn Sprague Dawley rats (B\&K Universal, Sollentuna, Sweden) were used. Adults, weighing between 200 and $300 \mathrm{gm}$, were kept under standardized conditions and given food and water ad libitum. Sixty-one adult rats were subjected to spinal cord weight-drop injury, and 27 were subjected to spinal cord transection. Fifty adult rats were included in a kainic acid experiment (35 were kainic acid treated and 15 were Ringer's solution treated), and 45 newborns were subjected to partial spinal cord transection. In Table 1, the number of animals killed at each time point for each individual experiment is displayed. In the SCI study of adult animals, no animals were lost before these determined time points. In the kainic acid study, two animals were lost. In the SCI study of newborn animals, one pup was lost. Animals were killed from $2 \mathrm{hr}$ to 6 months after injury. All experiments had been approved by the Stockholm Animal Ethics Committee.

\section{Surgery}

Dorsal laminectomies at the level of the ninth thoracic vertebra were carried out under general halothane (Fluothane, AstraZeneca) anesthesia.

Adults. The exposed spinal cord was either left untouched (sham), contused (weight-drop), or completely transected. Contusion injuries were performed using the NYU impactor (Gruner, 1992) and a $25 \mathrm{~mm}$ drop. Sterile 3/0 and 2/0 sutures (PDSII and Ethilon II, Ethicon) were used to suture muscle and skin, respectively. Animals were given antibiotics (Borgal, Hoechst) the first week after injury and thereafter if needed. Animals were allowed to recover from anesthesia in warmed cages. A heating pad was placed under a part of each cage during the first $3 \mathrm{~d}$ after the operation. Urinary bladders were emptied manually three times every day the first week and twice daily thereafter to prevent urinary tract infections.

Newborns. Under anesthesia, inspections of respiratory rate and skin color were made at close intervals. The depth of analgesia was assessed by the pedal withdrawal reflex. Laminectomies were followed by partial spinal cord transections of approximately two-thirds of the spinal cord width, cutting one side completely. The skin was sutured using sterile $6 / 0$ sutures (Vicryl, Ethicon). Pups were allowed to recover from anesthesia before being reunited with the dam. Delivery of halothane anesthesia to the newborn rats was according to Park and colleagues (1992).

\section{Kainic acid treatment}

Thirty-five adult rats were injected with kainic acid at a dose of $10 \mathrm{mg} / \mathrm{kg}$, i.p.; 15 animals were given saline as controls. All animals were observed for development of seizures. Kainic acid-injected animals included in this study $(n=24)$ developed grade V seizures (repeated incidences of rising on the hindlimbs and falling over) (Sperk et al., 1985). Control animals had no such symptoms. Animals were killed $2 \mathrm{hr}$ (three kainic acidtreated, three controls), $4 \mathrm{hr}$ (nine kainic acid-treated, four controls), $1 \mathrm{~d}$ 
(six kainic acid-treated, four controls), $3 \mathrm{~d}$ (three kainic acid-treated, two controls), and $7 \mathrm{~d}$ (three kainic acid-treated, three controls) after injection. Seizure activity was still evident $4 \mathrm{hr}$ after treatment. Twenty-four hours after treatment, animals had no overt signs of seizures.

\section{In situ hybridization}

Animals were decapitated, and brains and spinal cords were dissected at $2 \mathrm{hr}$ (weight-drop, $n=4$; adult sham, $n=2$ ), $6 \mathrm{hr}$ (weight-drop, $n=4$; adult sham, $n=2$; newborn partial transection, $n=5$; newborn sham, $n=$ 1), $12 \mathrm{hr}$ (newborn partial transection, $n=5$, newborn sham, $n=1$ ), $1 \mathrm{~d}$ (transection, $n=4$; weight-drop, $n=6$; adult sham, $n=1$; newborn partial transection, $n=5$; newborn sham, $n=1$ ), $3 \mathrm{~d}$ (transection, $n=2$; weight-drop, $n=4), 7 \mathrm{~d}$ (transection, $n=4), 10 \mathrm{~d}$ (transection, $n=4$ ), and 6 weeks (transection, $n=5$; weight-drop, $n=8$ ) after surgery. In addition, kainic acid-treated (see above), normal postnatal day 0 (P0) $(n=5)$, normal P1 $(n=2)$, and normal adult $(n=5)$ rats were included. Spinal cords and brains were rapidly dissected and frozen on dry ice. Although our efforts were focused on the spinal cord tissue, excluding dorsal root ganglia from quantification assessments, dorsal root ganglia served as a positive control tissue for many of the mRNA species not normally present in the spinal cord, such as p75. Cryostat sections (14 $\mu \mathrm{m})$ were collected from seven to eight levels of the spinal cords, ranging from cervical to sacral, and with a distance of $\sim 7 \mathrm{~mm}$ between adjacent levels. Sections were thawed to slides (ProbeOn, Fisher Biotech, Pittsburgh, PA). In situ hybridization was performed using radiolabeled oligonucleotide probes (Dagerlind et al., 1992). Probes complementary to GDNF (nucleotides 540-589) (Lin et al., 1993), NTN (970-1019) (Kotzbauer et al., 1996), PSP (261-310, 383-432) (Milbrandt et al., 1998), GFR $\alpha$-1 (1067-1112) (Sanicola et al., 1997), GFR $\alpha$-2 (1051-1094) (Baloh et al., 1997), RET (2527-2576) (Iwamoto et al., 1993), NGF (398-447) (Whittemore et al., 1988), BDNF (250-298) (Leibrock et al., 1989), NT3 (558-568) (Maisonpierre et al., 1990), NT4 (549-598) (Ip et al., 1992), TrkA (942-992) (Indo et al., 1997), TrkB (2567-2617) (Middlemas et al., 1991), truncated TrkB (167-211) (Middlemas et al., 1991), TrkC (1209-1259) (Merlio et al., 1992), p75 (873-920) (Radeke et al., 1987), GFAP (1397-1446) (Feinstein et al., 1992), and c-fos (489-538) (Curran et al., 1987) were used. All probes, except the ones complementary to GFR $\alpha$-3, have been characterized previously [GDNF (Nosrat et al., 1996); NTN and GFR $\alpha$-2 (Widenfalk et al., 1997); GFR $\alpha-1$ and RET (Nosrat et al., 1997a); NGF and NT3 (Wetmore and Olson, 1995); BDNF (Wetmore et al., 1990); NT4 (Nosrat et al., 1997b)] and do not match any known sequence in GenBank except those of the intended genes. A control 50-mer random probe (Nosrat and Olson, 1995) not complementary to any sequence deposited in GenBank was also used. After $3^{\prime}$ end-labeling with $\left[{ }^{35} \mathrm{~S}\right] \mathrm{dATP}$ (NEN DuPont) by terminal deoxynucleotidyl transferase (Amersham Pharmacia Biotech, Uppsala, Sweden), probes were purified (QIAquick Nucleotide Removal Kit Protocol, Qiagen, Hilden, Germany). Slides were incubated overnight $\left(42^{\circ} \mathrm{C}\right)$ with $0.1 \mathrm{ml}$ of hybridization mixture containing $50 \%$ formamide, $4 \times$ SSC $(0.15 \mathrm{M} \mathrm{NaCl}, 0.015$ sodium citrate, $\mathrm{pH} 7.0), 1 \times$ Denhardt's solution, $1 \%$ Sarcosyl, $0.02 \mathrm{M} \mathrm{Na}_{3} \mathrm{PO}_{4}, \mathrm{pH} 7.0,10 \%$ dextransulfate, 0.06 м DTT, 0.1 $\mathrm{mg} / \mathrm{ml}$ sheared salmon sperm DNA, and hot probe. Slides were then rinsed four times $(45 \mathrm{~min})$ in $1 \times \mathrm{SSC}$ at $60^{\circ} \mathrm{C}$. During a fifth rinse in $1 \times$ $\mathrm{SSC}$, the bath was allowed to adjust to room temperature. Further rinsing was performed in distilled water and increasing concentrations of ethanol. Slides were then air dried and dipped in emulsion (Kodak NTB2, diluted 1:1 with water) or exposed for 3 weeks on x-ray films (Hyperfilm$\beta$-max, Amersham) for quantification (see below). After 6 weeks of exposure, slides were developed, counterstained with cresyl violet, and mounted (Entellan, Merck). All hybridization was performed under high-stringency conditions. The control probe was hybridized and processed together with the other probes and gave rise to no specific pattern of hybridization signals.

Detection of positive autoradiographic signals was based on serial observations of adjacent sections from each tissue specimen, and accumulation of silver grains in the emulsion above specific cells and tissues was identified by the staining procedures. Only cells over which silver grain accumulation was clearly above surrounding background levels and could be confirmed by both dark-field and bright-field high magnification were regarded as positive.

Astrocytes and oligodendrocytes were distinguished by morphology and localization. Comparisons were made with adjacent sections hybridized with GFAP (astrocytes) and MAG (oligodendrocytes) mRNA probes. Clear distinction between the two glial cell types was sometimes difficult but could be accomplished, e.g., for reactive astrocytes near lesions and oligodendrocytes in horizontally sectioned spinal cord white matter, where oligodendrocytes typically line up in rows.

Quantification of x-ray films was performed blindly for all probes and treatments with specific labeling confirmed by microscopic observations on emulsion-dipped slides. Exceptions were BDNF and p75 mRNA probes, where the signals were restricted to a very small number of cells, making quantification from $x$-ray film exposures unsuitable. BDNF and p75 mRNA in situ hybridization signals instead were quantified using emulsion-dipped slides by counting the number of positively labeled cells per section. Two sections per spinal cord level (cervical $\sim 2 \mathrm{~cm}$ above lesion, thoracic immediately below the lesion, and lumbar $\sim 2.5 \mathrm{~cm}$ below the lesion) and animal were averaged, resulting in one value per level and animal. For probes analyzed using x-ray-films, treatment groups to be compared were exposed together on one x-ray film, enabling reliable between-group comparisons under standardized conditions. Occasionally artifacts precluded quantification of certain sections, resulting in different numbers of animals for different probes. No group included in quantification had fewer than four individuals. Hence, sham-operated, normal P2, kainic acid-treated animals killed 3 and $7 \mathrm{~d}$ after treatment were not included in quantifications. Only sections clearly devoid of artifacts were measured. X-ray films were developed and computer scanned, and quantification of the optical density was performed using image analysis software (NIH Image 1.62, National Institutes of Health, Bethesda, MD). Background levels were set to 0 and complete blackening of the film was set to 100 , and calibration was determined as a straight line between the two control values. The areas measured for each probe and experiment were as follows: c-fos and GFAP in the whole cross section; NGF in the meninges of adults at thoracic level (SCI); and the whole cross section including meninges in newborn; NT3 and TrkA in the whole cross section including meninges in newborn; truncated TrkB in both white and gray matter of adults and whole cross section in newborn; TrkB and TrkC in spinal cord gray matter (kainic acid and SCI experiments); GDNF in the meninges of adults at thoracic level (SCI) and in the whole cross section area including meninges in newborn; GFR $\alpha-1$ in spinal cord gray and white matter in adults and spinal cord gray matter in newborn; GFR $\alpha$-2 in the dorsal horns of adult spinal cords (kainic acid and SCI experiments) and in spinal cord gray matter in newborn; and RET in motoneurons of the ventral horns (kainic acid and SCI experiments). Spinal cords from adult normal and spinal cord-injured animals were analyzed at cervical, thoracic, and lumbar levels. When measurements were to be performed in gray matter, which was often absent at the level of the injury, a thoracic level was chosen immediately below the level of the lesion. Kainic acid-treated animals were quantified at the lumbar level. Spinal cords of newborn animals were analyzed at the level of the injury (thoracic) and below (lumbar).

\section{Ribonuclease protection assay}

Six spinal cords each were collected from normal newborn (P0) rats, as well as $12 \mathrm{hr}$ and $1 \mathrm{~d}$ after partial spinal cord transection in newborn rats. Eight spinal cords each were collected from normal adult rats, $1 \mathrm{~d}$ after complete transection and 6 weeks after weight-drop injury. Spinal cords of adults and spinal cords with adjacent parts of the vertebral column of newborn animals were rapidly dissected and frozen on dry ice. Pieces of adult spinal cord ( $\sim 10 \mathrm{~mm}$ long) were collected starting from the lesion center and reaching $1 \mathrm{~cm}$ caudally. From neonates, 7-mm-long tissue pieces, with the lesion located centrally and thus containing the whole spinal cord lesion, were collected. RNA was extracted by phenolchloroform extraction (RNAgents Total RNA Isolation System, Promega) followed by purification (RNeasy Mini kit, Qiagen). The ribonuclease protection assay (RPA) protocol was according to instructions (Ambion RPAIII, modified protocol for PharMingen Riboquant multiprobe template sets) and $\left[{ }^{32} \mathrm{P}\right]$-labeled probes (Riboprobe in vitro Transcription System, Promega). Equal amounts of total RNA $(6 \mu \mathrm{g})$ were hybridized, using probes complementary to rat NGF, BDNF, GDNF, CNTF, NT3, NT4, L32, and GADPH (Rat multi-probe template set rNT-1, Riboquant, PharMingen). Protected cRNA fragments were separated by denaturing $5 \%$ polyacrylamide gel electrophoresis. X-ray films were exposed to the gels overnight (for pictures) and to phosphoimager plates for $3 \mathrm{hr}$ (for quantifications). Quantification using computer software connected to a phosphoimaging system (IBAS3000, BAS reader, Raytest Isotopenmessgeräte) was performed by measuring the average radioactivity per square millimeter for each band. The housekeeping gene L32 was used as an internal standard, ensuring RNA integrity and equal RNA loading. 
Table 2. Antibodies used in the present study

\begin{tabular}{llll} 
Antibody & Concentration & Origin & Company \\
\hline CAMkinase II & $1: 500$ & Monoclonal & Life Technologies, Cat. No. 13231-014 \\
GAP-43 & $1: 500$ & Monoclonal & Chemicon, MAB 347 \\
GFAP & $1: 1000$ & Polyclonal, rabbit & Sigma \\
GFR $\alpha-1$ & $1: 100$ & Polyclonal, goat & R \& D Systems, Cat. No. AF560, lot BQE01 \\
Serotonin & $1: 1000$ & Polyclonal, rabbit & Sigma, S-5545 \\
Tyrosine hydroxylase & $1: 500$ & Polyclonal, rabbit & Interassay, p40101-0, lot 25720 \\
Vimentin & $1: 100$ & Monoclonal & Dako, M0725 \\
\hline
\end{tabular}

\section{Immunohistochemistry and counterstaining}

Normal adult animals $(n=8)$, weight-drop injured ( 1 week, $n=8 ; 6$ weeks, $n=8 ; 6$ months $n=1)$ animals, and adult animals subjected to partial spinal cord transection as newborn $(n=3)$ were anesthetized deeply by intraperitoneal injections of pentobarbital and intracardially perfused with $50 \mathrm{ml}$ of Tyrode's solution, containing $0.1 \mathrm{ml}$ of 5000 $\mathrm{IOU} / \mathrm{ml}$ heparin (Løvens), followed by $200 \mathrm{ml}$ fixative (4\% paraformaldehyde and $0.4 \%$ picric acid in PBS). Spinal cords were carefully dissected and post-fixed for $1 \mathrm{hr}$ in fixative (4\% paraformaldehyde and $0.4 \%$ picric acid in PBS), rinsed several times in $10 \%$ sucrose in PBS, and stored at $4^{\circ} \mathrm{C}$ until sectioned. Cryostat sections (14 $\mu \mathrm{m}$ thick) were taken at seven to eight spinal cord levels with $7 \mathrm{~mm}$ intervals, and primary antibodies were applied overnight at room temperature. The primary antibodies that were used are listed in Table 2. Secondary antisera were conjugated with FITC or rhodamine (Jackson ImmunoResearch) and usually diluted 1:50. For each spinal cord and antibody, $\sim 100$ sections collected from cervical to lumbar level and mounted on five to seven slides, were microscopically examined regarding immunoreactivity. Control slides treated with secondary antibodies were examined in parallel. Double-labeling with GFAP and GFR $\alpha-1$ antibodies was used to confirm astrocyte labeling.

Quantification of the intensity of GFR $\alpha-1$ immunoreactivity was performed on a blind basis using computer image analysis equipment (Nikon, Microphot-FXA; ZVS-47EC CCD video camera). The dorsal roots of 16 weight-drop-injured ( 1 week, $n=8 ; 2$ weeks, $n=8$ ) and 8 normal animals were included. The weight-drop-injured animals were analyzed at two levels: the cervical level and the level of the injury. The intensities of GFR $\alpha-1$ immunoreactivity in one cervical and one thoracic dorsal root were measured in two sections for each animal and averaged, resulting in one value per animal and level. When GFR $\alpha-1$ immunoreactivity was quantified in spinal cord white matter of cervical dorsal funiculi, normal, degenerating (the portion hosting ascending sensory fibers), and nondegenerating white matter (the portion hosting descending fibers such as the corticospinal tract) of the cervical dorsal funiculi were measured separately in two sections per animal, yielding one value for each tissue and animal. Comparisons were made between dorsal roots at cervical and thoracic levels 1 week after injury, and normal/ degenerating/nondegenerating spinal cord white matter tissue at cervical levels 6 weeks after injury.

\section{Behavior tests}

Behavior analyses of adult animals subjected to a partial spinal cord transection as newborns were performed by BBB scoring (Basso et al., 1995) and a grid pathway test (Grill et al., 1997). The BBB score for evaluation of hindlimb function after SCI ranges from 0 , which corresponds to flaccid paralysis, to 21, which is normal gait. Animals were allowed to walk around freely in a circular field $(1.2 \mathrm{~m}$ in diameter) for 4 min while movements of the hindlimbs were closely observed. Ranking according to the scoring system described by Basso and colleagues (1995) includes frequency and quality of hindlimb movement as well as forelimb/hindlimb coordination. In the grid pathway test, animals are allowed to walk three times voluntarily across a 1.2 -m-long grid pathway. The number of errors (hindlimbs stepping through the grid) was counted for each crossing. The three values were averaged and resulted in one value per animal. Four adult animals, which were partially spinal cord transected as neonates, were examined with respect to their hindlimb function 6 months after injury. For comparison in the grid pathway test, 20 normal animals were also examined. Six months after injury, animals were tested on two occasions $2 \mathrm{~d}$ apart. Although both sessions gave rise to similar results, the statistics of only one session are presented in Results.

\section{Statistical analyses and image processing}

Statistical analyses used for comparison of different in situ hybridization probe signals and RPA autoradiograms included factorial ANOVA followed by a Fisher's post hoc test. Data from the grid pathway test were analyzed using an unpaired $t$ test (confidence interval 95\%). For statistical analyses of the GFR $\alpha-1$ immunohistochemistry, an unpaired $t$ test (confidence interval 95\%) and ANOVA followed by a Fisher's post hoc test were used. Significance levels were defined as follows: ${ }^{*} p<0.05$; $*^{*} p<0.01 ; * * * p 0.001$. Photomicrographs were scanned, digitally processed, and compiled using computer image software. Occasional particles of dust and other obvious artifacts were digitally retouched.

\section{RESULTS}

\section{Mechanical injury of rat spinal cord}

Lesion characteristics

Adult. Complete transections lead to severe damage of the spinal cord restricted to the level of injury, whereas weight-drop injuries lead to the characteristic egg-shaped zone of necrosis (Fig. 1A) extending several spinal cord segments rostrocaudally. One important difference between the two injury models is that in weight-drop injuries the dura is left mechanically intact, whereas in the transection model the dura is cut, exposing the spinal cord. Cutting the dura has severe consequences for the cerebrospinal flow and may aggravate secondary degenerative processes. It could also induce repair responses in meningeal cells other than those seen after contusion injury.

In the necrosis zone of contused animals, mRNA signals were generally lost because of absence of living spinal cord neurons and glia (Fig. 1A). This loss of signal was seen for all investigated neurotrophic factor and neurotrophic factor receptor mRNA species and is not described below for each individual mRNA species. Likewise, the absence of hybridization signals in the lesion area after transections caused by necrosis is not detailed below. The astroglial response, monitored by probes for GFAP mRNA after weight-drop and transection injury, is shown in Figure 1. GFAP mRNA hybridization signals increased gradually up to the latest time point investigated, 6 weeks after injury (Fig. $1 B-J$ ) (quantification data not shown), and the upregulation was observed primarily in degenerating fiber tracts at cervical, thoracic, and lumbar levels (Fig. $1 D, G, J$ ). The mRNA expression of the immediate-early gene c-fos was also investigated to further characterize the glial and neuronal response to injury. In normal intact spinal cord, c-fos mRNA was restricted to a few cells in the dorsal root entry zone. After mechanical SCI, c-fos mRNA signals were upregulated at all times investigated, the strongest for weight-drop injury being $1 \mathrm{~d}$ after injury (Figs. $2 A, B, 3 A, F, K$ ). One day after injury, strong c-fos mRNA signals were found close to the injury in glial cells, primarily astrocytes, and in neurons. 


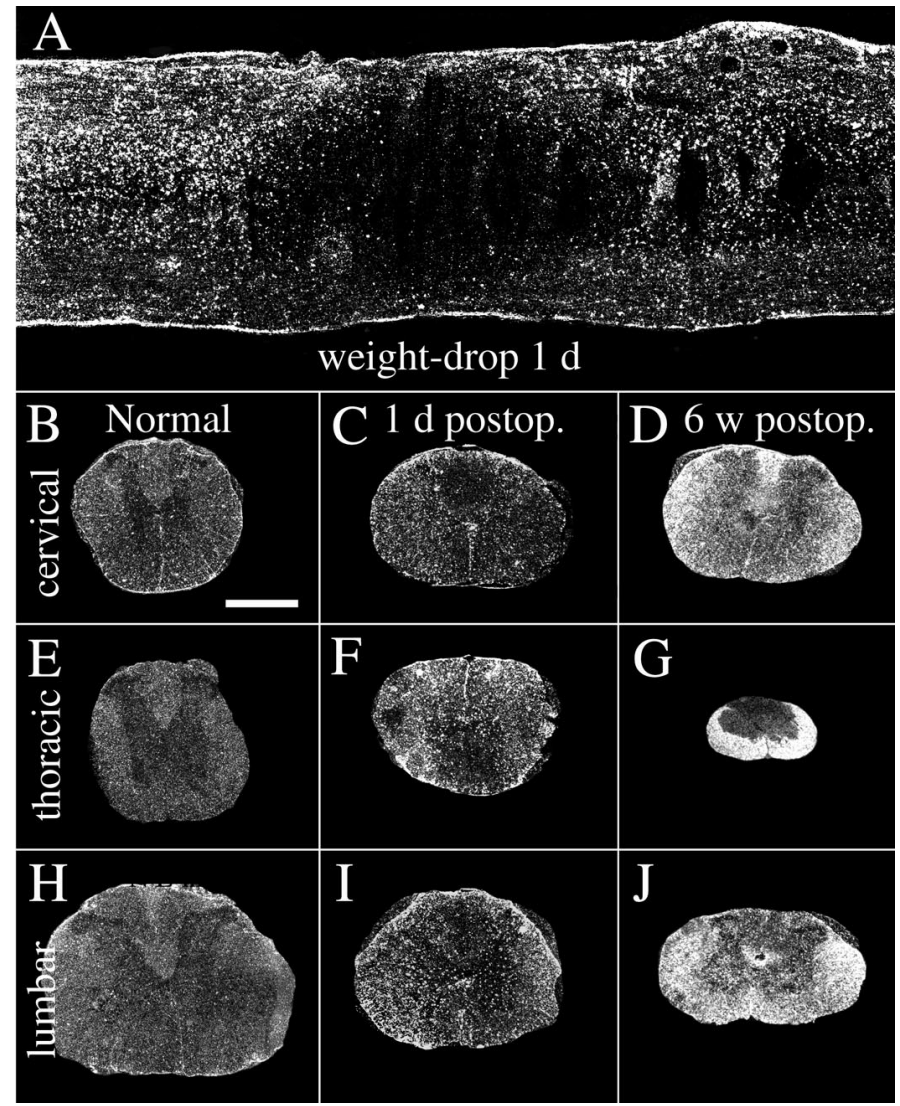

Figure 1. Dark-field photomicrograph depicting GFAP mRNA in situ hybridization signals in normal and weight-drop-injured adult spinal cord. $A$, Horizontal section showing the lesion area $1 \mathrm{~d}$ after injury. The primary lesion zone with the shape of an ellipse is characterized by markedly reduced mRNA synthesis, whereas cells surrounding the lesion are strongly positive for the GFAP mRNA probe. $B, E, H$, GFAP mRNA hybridization signals in normal uninjured spinal cord at cervical, thoracic, and lumbar levels. $C, F, I$, One day after SCI, GFAP mRNA signals have increased at the thoracic level close to the lesion $(F)$ but also at cervical $(C)$ and lumbar levels $(I)$. Note increased signals in cells around the central canal at cervical and lumbar levels. $D, G, J$, Six weeks after injury, strong GFAP mRNA expression is present in degenerated white matter, especially at the level of injury $(G)$. Degenerating white matter fiber tracts, such as the ascending sensory tract in the dorsal funiculus above the lesion $(D)$, and the descending corticospinal tract below the lesion in the dorsal funiculus $(J)$, are also strongly labeled. Scale bar (shown in $B$ ): $A, 650 \mu \mathrm{m} ; B-J, 1 \mathrm{~mm}$.

Strong c-fos labeling was also observed in ependymal cells of the central canal. At cervical levels $1 \mathrm{~d}$ after weight-drop injury, c-fos-labeled neurons were found in laminas VII-VIII and at lumbar levels IV-VII and X. Six weeks after injury, glial cells, primarily astrocytes, and neurons close to the lesion expressed low levels of c-fos mRNA. At cervical and lumbar levels 6 weeks after injury only low levels of c-fos were found, restricted to a few cells located in the same laminas as $1 \mathrm{~d}$ after injury.

Newborn. Partial transection injuries penetrating the dura in newborn rat spinal cord led to severe local injury. Moderate increases of GFAP mRNA (Fig. $4 A-F$ ) and strong increases of c-fos mRNA (Fig. $2 C, D$ ) were observed $1 \mathrm{~d}$ after the operation. In the necrosis zone, mRNA signals were generally lost because of the absence of living spinal cord cells (Fig. 4D). This loss of signal was seen for all investigated neurotrophic factor and neurotrophic factor receptor mRNA species and is not described below for each individual mRNA species. A few of the animals that were
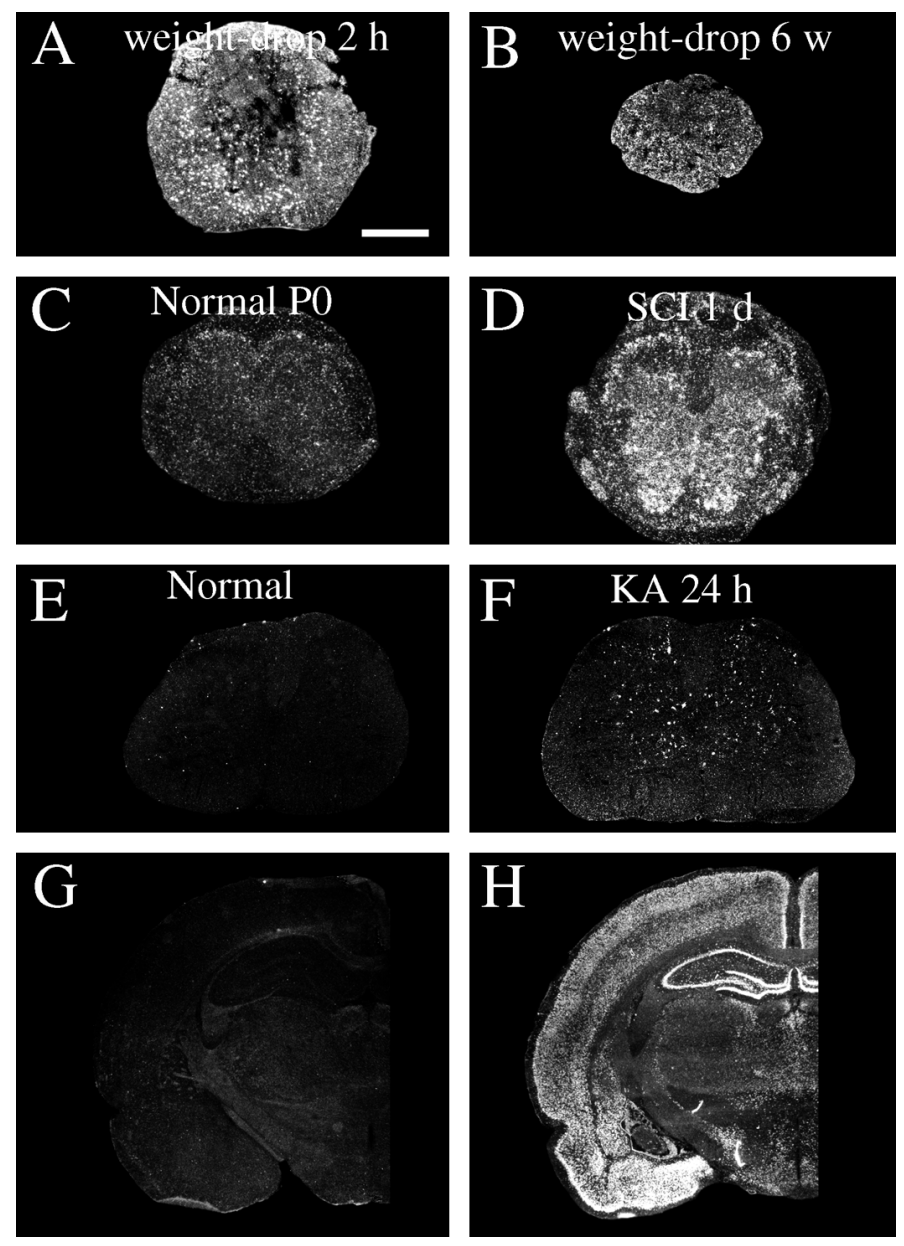

Figure 2. Alterations of c-fos mRNA expression in response to SCI and kainic acid delivery. $A$, Two hours after weight-drop injury of the adult spinal cord, glial cells and neurons present strong c-fos mRNA signals close to the lesion. $B$, Six weeks after injury, glial cells and some neurons close to the injury are still positively labeled by the c-fos probe. $C$, A weak $\mathrm{c}$-fos mRNA expression is found in newborn $(P 0)$ spinal cord. $D$, One day after partial transection of the newborn spinal cord (SCI $1 d$ ), robust c-fos mRNA upregulations occur primarily in cells of the gray matter and in nerve roots. $E$, In normal adult rat spinal cord, very low levels of c-fos mRNA were found. $F$, One day after kainic acid delivery, scattered neurons in Rexed's laminas III-V II present strong c-fos mRNA signals. $G$, In a normal brain (the brain of the animal depicted in $E$ ), no robust c-fos mRNA signals can be found. $H$, One day after kainic acid delivery (the brain of the animal depicted in $F$ ), dramatic c-fos hybridization signals appear in areas such as the neocortex, the hippocampal formation, and amygdala. Scale bar (shown in $A$ ): $A, B, G, H, 1 \mathrm{~mm} ; C, D, 2 \mathrm{~mm} ; E$, $F, 300 \mu \mathrm{m}$.

allowed to grow to adulthood were investigated regarding behavior and general histology. Compared with normal uninjured controls, animals receiving a partial transection as newborns showed only minor behavior differences. No difference could be found using the BBB score for hindlimb function; all animals scored the highest possible value, 21. However, when we used the grid pathway test used previously to assess corticospinal tract regeneration functionally (Grill et al., 1997), animals receiving a partial transection as newborns were found to make a higher number of errors, $2.83 \pm 0.30$ (mean \pm SEM), compared with controls $0.97 \pm 0.15$ (unpaired $t$ test; $p<0.001$; df $=22 ; t=5.2$ ). Spinal cords of treated animals displayed a markedly decreased crosssection area at the level of injury compared with normal spinal 

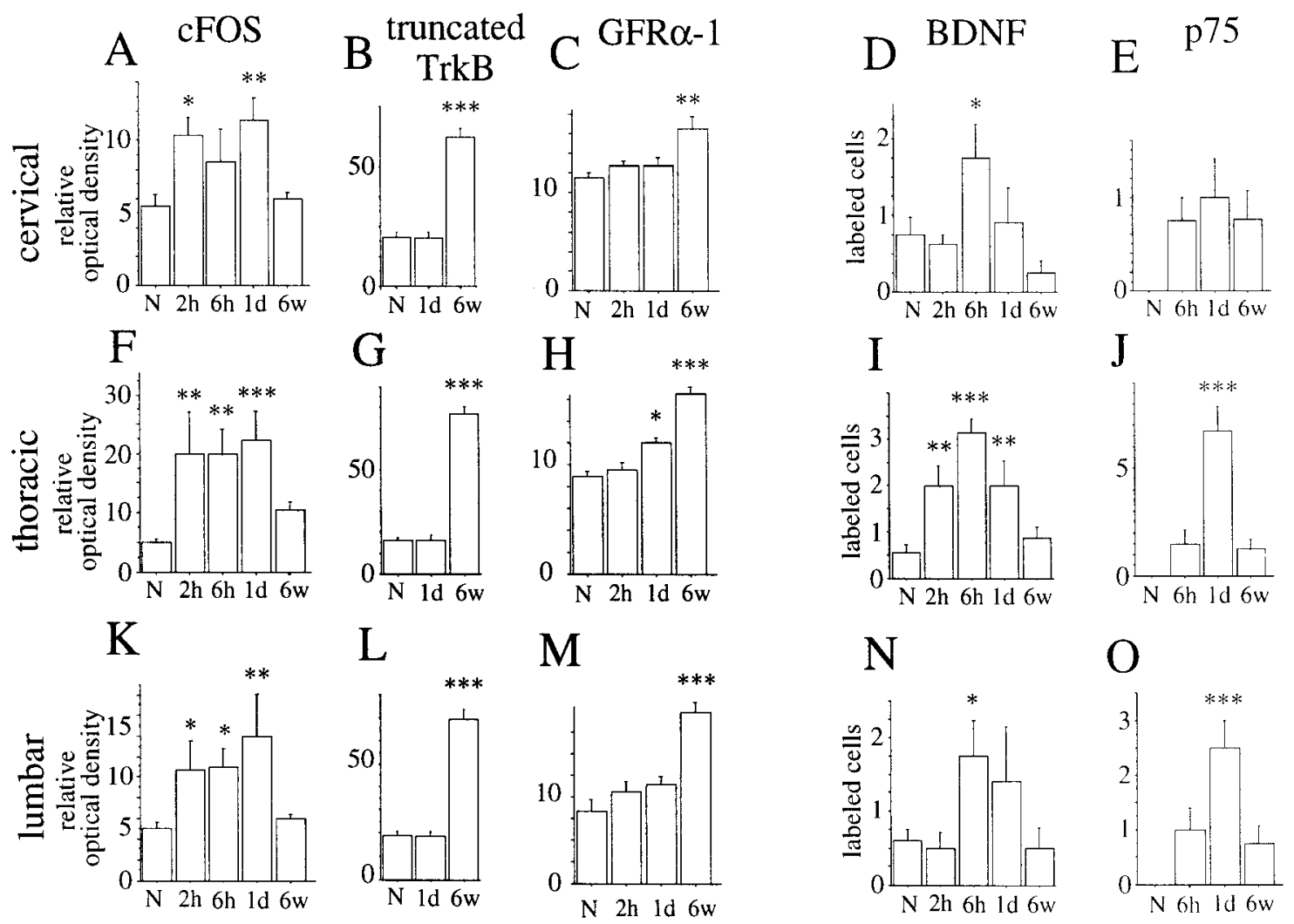

Figure 3. Regulation of different mRNA species in the spinal cord after weight-drop injury as monitored by in situ hybridization. Quantifications of c-fos, truncated TrkB, and GFR $\alpha-1$ were performed by measuring the relative optical density on x-ray films exposed to hybridized sections. Quantifications of $\mathrm{BDNF}$ and $\mathrm{p} 75$ were performed by counting the number of positively labeled cells per section. All statistical comparisons were made to normal animals $(N)$. A, At the cervical level c-fos was significantly increased at $2 \mathrm{hr}$ and $1 \mathrm{~d}$ after injury $\left(F_{(4,20)}=4.9 ; p<0.01\right)$. B, Significant increase of truncated TrkB in white matter at cervical levels was found 6 weeks after surgery $\left(F_{(3,18)}=48 ; p<0.001\right) C$, At the cervical level significant upregulation of GFR $\alpha-1$ mRNA in white matter was found 6 weeks after injury $\left(F_{(4,21)}=3.3 ; p<0.05\right)$. D, The number of BDNF mRNA-labeled cells was significantly increased $6 \mathrm{hr}$ after injury $\left(F_{(4,24)}=3.3 ; p<0.05\right)$. E. There was an increase in the number of p75 cells $6 \mathrm{hr}, 1 \mathrm{~d}$, and 6 weeks after injury at the cervical level, but the difference compared with normal was not statistically significant. $F$, At the thoracic level c-fos was significantly increased at $2 \mathrm{hr}, 6 \mathrm{hr}$, and $1 \mathrm{~d}$ after injury $\left(F_{(4,20)}=6.6 ; p<0.01\right)$. $G$, A significant increase of truncated TrkB in white matter at the thoracic level was found 6 weeks after surgery $\left(F_{(3,18)}=108 ; p<0.001\right) . H$, At the thoracic level significant upregulation of GFR $\alpha-1 \mathrm{mRNA}$ in white matter was found 6 weeks after injury $\left(F_{(4,21)}=\right.$ $28 ; p<0.001) . I$, The number of BDNF mRNA-labeled cells was significantly increased at the thoracic level $2 \mathrm{hr}, 6 \mathrm{hr}$, and $1 \mathrm{~d}$ after injury $\left(F_{(4,24)}=\right.$ $11 ; p<0.001) . J$, The number of $\mathrm{p} 75$ probe-labeled cells was elevated at $6 \mathrm{hr}, 1 \mathrm{~d}$, and 6 weeks after injury at the thoracic level. The difference was significant after $1 \mathrm{~d}\left(F_{(3,17)}=21 ; p<0.001\right) . K$, c-fos mRNA expression levels were significantly increased $2 \mathrm{hr}, 6 \mathrm{hr}$, and $1 \mathrm{~d}$ after injury $\left(F_{(4.20)}=5.1\right.$; $p<0.01)$. $L$, A significant increase of truncated TrkB in white matter at lumbar levels was found 6 weeks after surgery $\left(F_{(3,18)}=54 ; p<0.001\right)$. $M$, At the lumbar level significant upregulation of GFR $\alpha-1$ mRNA in white matter was found 6 weeks after injury $\left(F_{(4,21)}=14 ; p<0.001\right)$. $N$, The number of BDNF mRNA-labeled cells was significantly increased at the lumbar level $6 \mathrm{hr}$ after injury $\left(F_{(4,30)}=3.1 ; p<0.05\right)$. $O$, The number of p75 mRNA-labeled cells was elevated at $6 \mathrm{hr}, 1 \mathrm{~d}$, and 6 weeks after injury at the thoracic level. The increase was significant after $1 \mathrm{~d}\left(F_{(3,17)}=8 ; p<0.01\right)$.

cords. The white matter of the lesioned side was reduced at the level of the lesion and several millimeters above and below (Fig. 5). Examination of 5HT- and TH-positive fibers above and below lesion revealed no gross anatomical disturbances of those systems. The dorsal corticospinal tract can be labeled by GAP-43 and CAM kinaseII in the normal intact adult rat spinal cord (Terashima, 1995). In animals receiving a partial transection as newborns and studied in adulthood, the dorsal corticospinal tract exhibited GAP-43 and CAM kinaseII immunoreactivity above the lesion. Below the lesion these two immunoreactivities were lacking in the expected position, supporting an altered development of the corticospinal tract in neonatally injured rats as shown previously for this kind of lesion (Bernstein and Stelzner, 1983).

\section{Neurotrophins and related receptors}

$\operatorname{Trk} A$. TrkA mRNA hybridization signals were not found in normal uninjured adult spinal cord. A subpopulation of dorsal root ganglia neurons was positively labeled in adults (Fig. 6D) as well asin neonates (Fig. 7B). No robust upregulations could be detected in the spinal cord white or gray matter at any time point after SCI in either neonates or adults. However, in neonatal dorsal roots, TrkA mRNA signals were upregulated on the affected side 6, 12, and $24 \mathrm{hr}$ after injury (data not shown).

TrkB. TrkB mRNA in spinal cords of normal uninjured adult (Fig. 6F) and newborn (Fig. 7D) animals was present in most neurons of the gray matter throughout the spinal cord and in a subpopulation of dorsal root ganglia neurons. Expression patterns were in agreement with previous findings (Klein et al., 1990; Ernfors et al., 1992). No robust alteration of full-length TrkB message could be detected in the spinal cord at any time point after injury in either adult or newborn animals.

Truncated TrkB. Truncated TrkB mRNA signals, defined as signals seen in areas where the full-length TrkB probe was negative, were fairly weak and found in white matter tissue of the normal uninjured adult spinal cord in agreement with Frisén et al. 

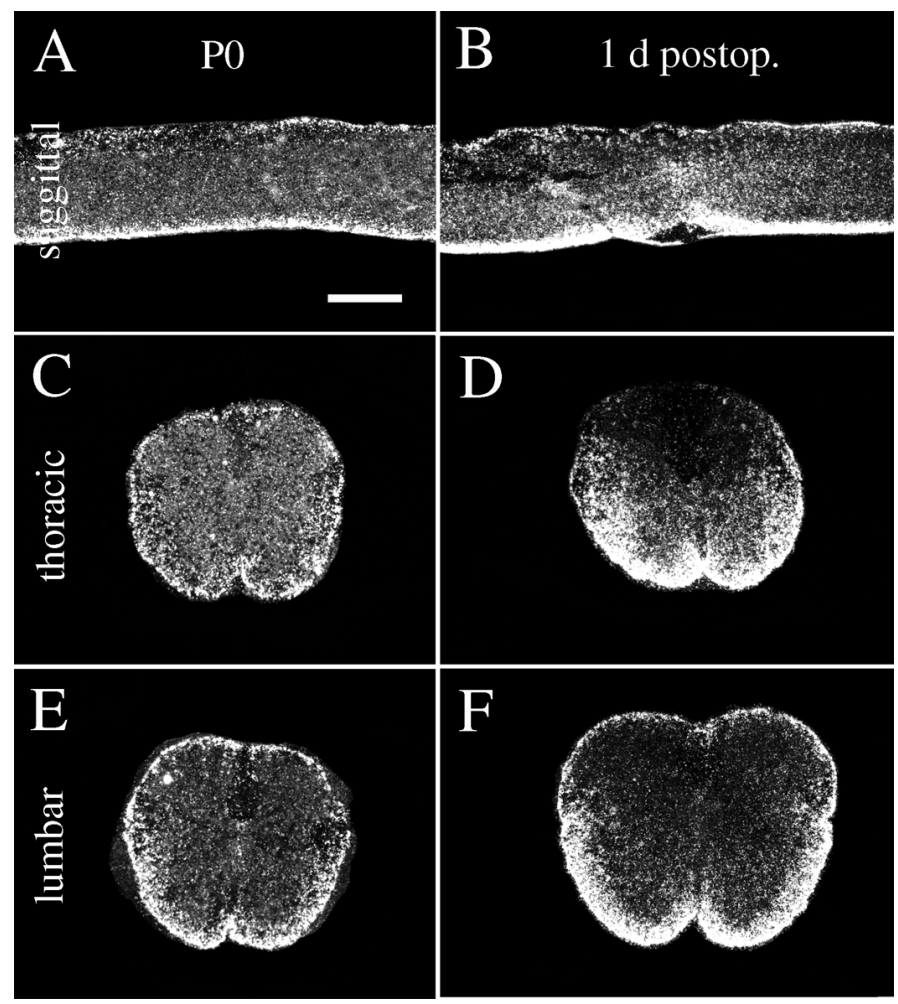

Figure 4. Dark-field photomicrograph depicting GFAP mRNA in situ hybridization signals in normal and injured neonatal spinal cord. $A, C, E$, GFAP mRNA hybridization signals in normal uninjured neonatal spinal cord. $B, D, F$, One day after injury GFAP mRNA expression is increased in tissue close to the lesion $(B, D)$ and slightly increased in ventral white matter at the lumbar level $(F)$. Scale bar (shown in $A$ ): $A, B, 600 \mu \mathrm{m} ; C-F$, $300 \mu \mathrm{m}$.

(1992). Upregulation after SCI was found $6 \mathrm{hr}$ after surgery, and increased expression continued up to the latest time point investigated, which was 6 weeks after injury. Figure 8 depicts truncated TrkB mRNA hybridization signals in normal spinal cord and at selected time points after injury. Six weeks after injury a strong truncated TrkB mRNA hybridization signal was present in degenerating fiber tracts of the white matter along the whole length of the spinal cord (Fig. 8C, $F, I$ ). For instance, the ascending fiber tract of the dorsal funiculus was strongly positive above the lesion (Fig. 8C) and weakly labeled below (Fig. 8I). The expression pattern of truncated TrkB resembles the distribution of GFAP mRNA expression (see above) or vimentin expression (data not shown) at similar time points, suggesting that cells were mainly reactive astrocytes (Eddleston and Mucke, 1993). No specific robust truncated TrkB signals could be found in oligodendrocytes, although we cannot rule out the possibility that some oligodendrocytes were positive. Close to weight-drop injury or transection injury signals were strong in both gray and white matter. The upregulations were statistically significant in both white and gray matter, although much more prominent in white matter (Fig. 3B, G,L). Microscopic observations suggest that the increase was confined to glial cells, although we cannot rule out a minor increase of truncated TrkB mRNA expression in neurons. No robust truncated TrkB mRNA labeling could be found in the scar tissue 6 weeks after injury (Fig. 8J). Ependymal cells of the central canal were positively labeled (Fig. $8 J$ ). In normal newborn animals, truncated TrkB mRNA signals were present in cells of the white matter (Fig. $7 F$ ). No robust

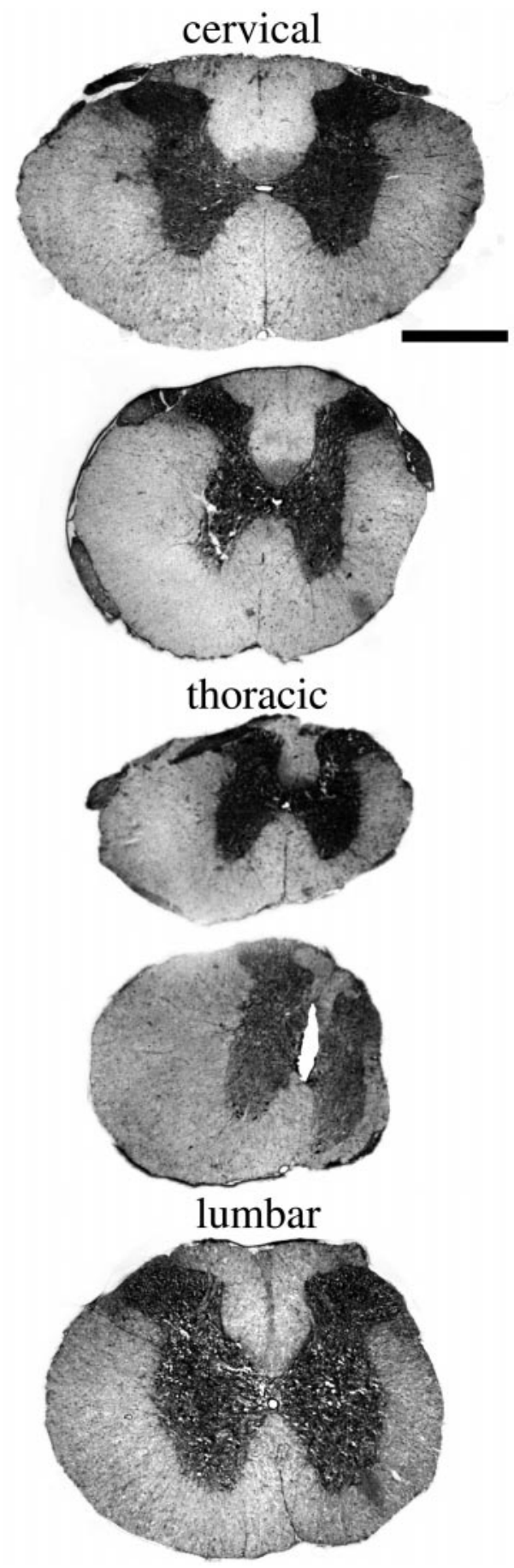

Figure 5. Appearance of the adult spinal cord of neonatally injured animal. Five levels, cervical to lumbar, of a spinal cord collected from an adult individual that underwent a partial spinal cord transection as newborn. A cut spanning approximately two-thirds of the width of the thoracic spinal cord beginning from the right side was carried out on the first postnatal day, a time point when long nerve fiber tracts, such as the corticospinal tract, are developing. The white matter of the cut side is reduced in size at all levels, but most prominently at thoracic levels close to the injury. This animal scored 21 (= normal) on the BBB score as an adult. Luxol fast blue was used for staining. Scale bar, $1 \mathrm{~mm}$.

upregulation could be found during the postoperative period investigated.

TrkC. TrkC mRNA hybridization signals in normal uninjured adult as well as newborn (Fig. $7 H$ ) spinal cord were found in 

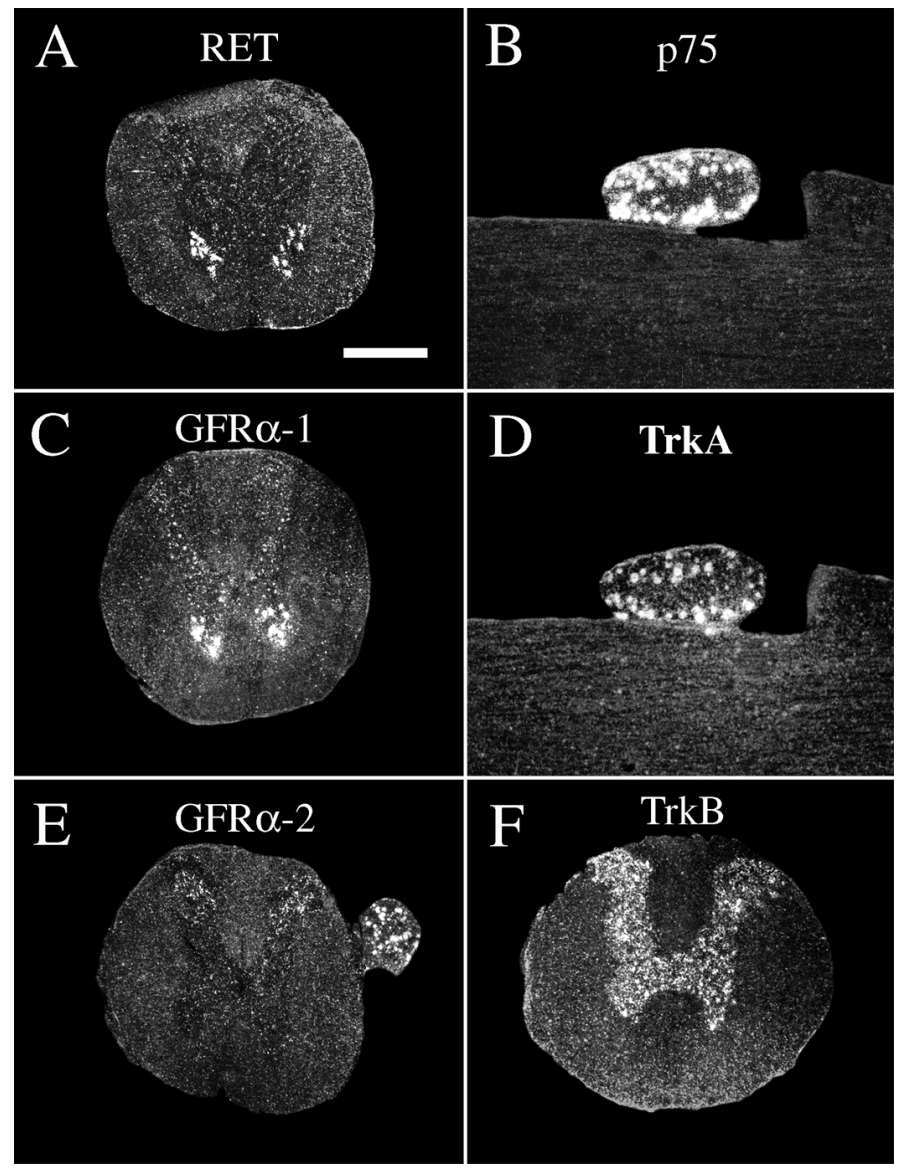

Figure 6. Expression of mRNA encoding neurotrophic factor receptors in the intact normal spinal cord of the adult rat. $A$, RET mRNA signals are seen in motoneurons. $B$, p75 mRNA signals were not detectable in spinal cord gray or white matter but were detectable in a subpopulation of dorsal root ganglia neurons, which is shown here in a horizontal section of cervical spinal cord. $C$, GFR $\alpha-1$ mRNA signals are present in motoneurons and interneurons. $D$, TrkA mRNA expression was not found in spinal cord gray or white matter but was found in a subpopulation of dorsal root ganglia neurons, which is shown here in a horizontal section of cervical spinal cord (section adjacent to $B$ ). $E$, GFR $\alpha-2$ mRNA signals are seen in the dorsal horns of gray matter and in a subpopulation of dorsal root ganglia neurons. $F$, TrkB mRNA synthesis occurs throughout the gray matter. Scale bar (shown in $A$ ): $A-F, 700 \mu \mathrm{m}$.

motoneurons and most other neurons in gray matter and a subpopulation of dorsal root ganglia neurons, in agreement with previous studies (Ernfors et al., 1992; Merlio et al., 1992; Elkabes et al., 1994). No robust upregulation of TrkC mRNA could be detected in the spinal cord at any time point after injury.

p75. p75 mRNA expression could not be detected in normal uninjured adult spinal cord, in agreement with previous findings (Ernfors et al., 1989). A subpopulation of adult dorsal root ganglia neurons was positive (Fig. $6 B$ ). After both weight-drop and transection injury, p75 mRNA hybridization signals upregulated in neurons, especially in close proximity to the lesion, where most neurons including motoneurons were labeled, but also at cervical and lumbar levels (Figs. 3E,J,O, 8L). Positively labeled neurons at a distance from the injury were present in Rexed's laminas V-IX, varying with time after injury and level. Most neurons were found in lamina VII. No robust upregulation of p75 mRNA could be found in pyramidal layer $\mathrm{V}$ cells of the cerebral hindlimb motor cortex after injury in adult animals (data not shown). In newborns, p75 mRNA signals were found in ventral horns and a
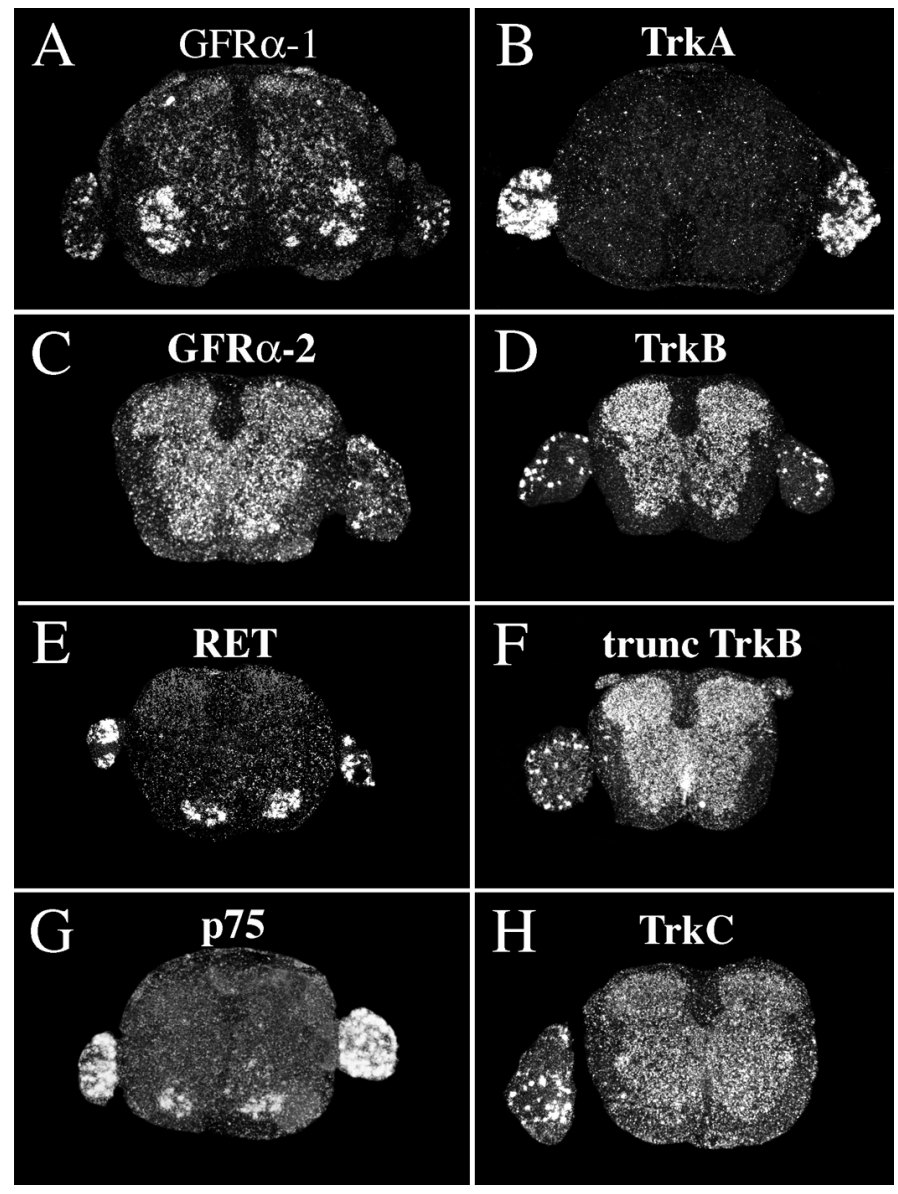

Figure 7. Expression of mRNA encoding neurotrophic factor receptors in the intact normal spinal cord of newborn rat. $A$, GFR $\alpha-1$ mRNA signals are found throughout the gray matter, with motoneurons displaying particularly strong signals, and in a subpopulation of dorsal root ganglia neurons. $B$, TrkA mRNA expression is present in dorsal root ganglia neurons. $C$, GFR $\alpha-2$ mRNA signals are found throughout the gray matter and in a subpopulation of dorsal root ganglia neurons. $D$, TrkB mRNA synthesis occurs throughout the gray matter and in some dorsal root ganglia neurons. $E$, RET mRNA signals were confined to motoneurons and a subpopulation of dorsal root ganglia neurons. $F$, The probe directed against truncated TrkB plus full-length TrkB-labeled cells in dorsal root ganglia and spinal cord gray and white matter. $G$, p75 mRNA signals are seen in motoneurons and many dorsal root ganglia neurons. $H$, TrkC mRNA expression is present throughout gray matter and in many dorsal root ganglia neurons. Scale bar (shown in $A$ ): $A-H, 170 \mu \mathrm{m}$.

subpopulation of dorsal root ganglia neurons (Fig. $7 G$ ). No change in expression levels was found in newborns in response to injury.

$B D N F$. BDNF mRNA expression in normal uninjured adult spinal cord was detected only in a few neurons of gray matter restricted to Rexed's lamina VII, in good agreement with previous findings (Conner et al., 1997). Counting of positively labeled neurons revealed an increase in the number of positively labeled cells in spinal cord gray matter of injured animals (Fig. 3D,I,N). The BDNF mRNA signals after injury were found in laminas IV, $\mathrm{V}$, and VII. RPA assays demonstrated an increase in BDNF mRNA in the adult spinal cord $1 \mathrm{~d}$, but not 6 weeks, after injury (Figs. 9I, 10B). In neonatal spinal cord, weak BDNF mRNA signals were found in some gray matter cells. A subpopulation of dorsal root ganglia cells of both neonatal and adult animals was strongly positive (data not shown), in agreement with previous 

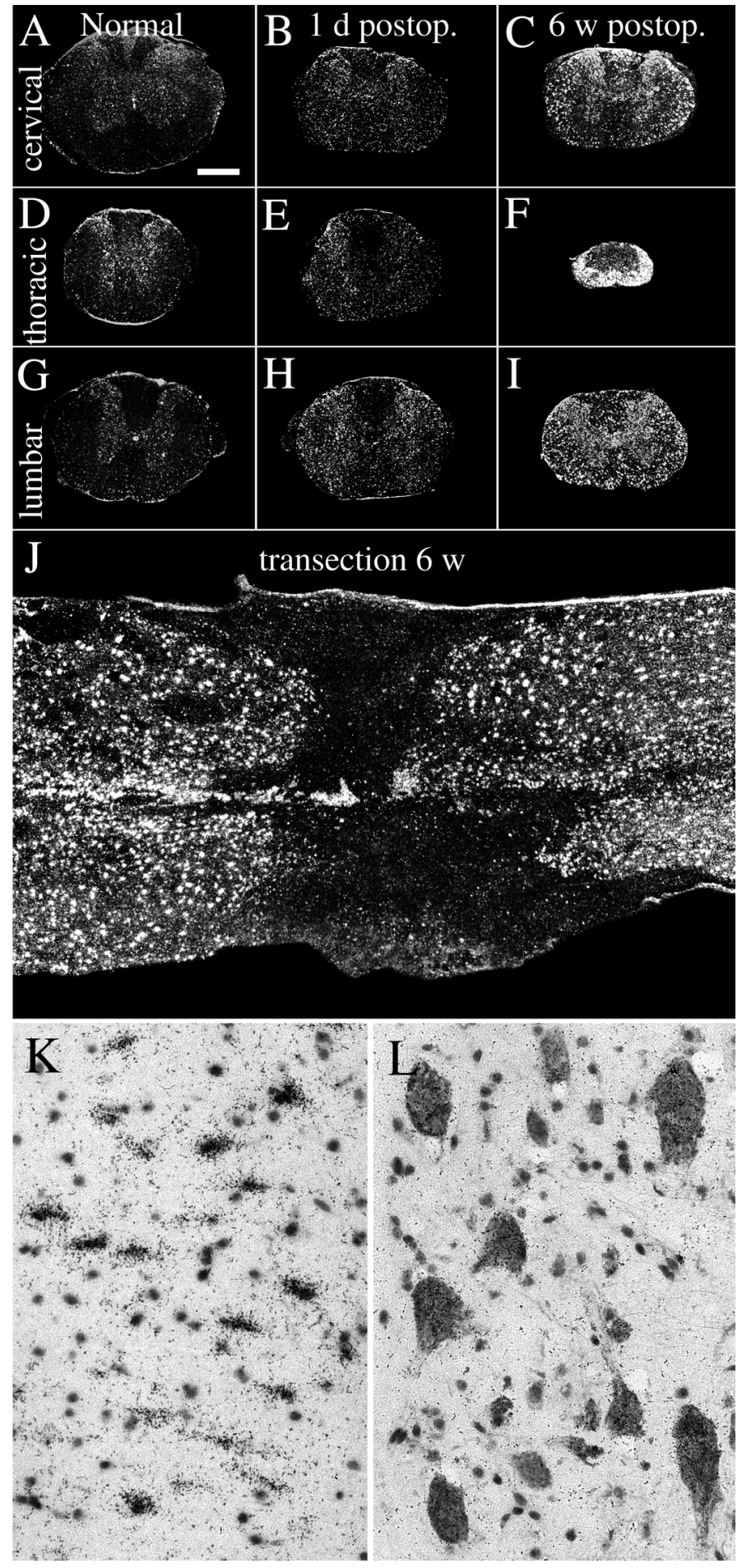

Figure 8. Truncated TrkB and p75 mRNA are both upregulated after injury to the adult spinal cord. Hybridization was performed with a probe that recognizes both truncated and full-length TrkB. The expression of truncated TrkB was deduced from comparisons with the expression pattern of the full-length-specific TrkB probe. No robust increases in hybridization signals could be detected when using a probe only complementary to full-length TrkB. $A, D, G$, The expression of full-length TrkB and truncated TrkB mRNAs in normal uninjured spinal cord is found in neurons of the gray matter and glial cells, respectively. $B, E, H$, One day after injury glial cells near the injury upregulated truncated TrkB mRNA signals $(E)$. The truncated TrkB mRNA expression is also increased to some extent at cervical and lumbar levels $(B, H) . C, F$, $I$, Six weeks after injury, white matter tissue at the injury level is strongly positive for truncated TrkB probe $(F)$. In addition, the truncated TrkB mRNA findings (Ernfors et al., 1992). Partial transection of the spinal cord in newborns led to no robust alteration of BDNF mRNA in the spinal cord tissue at the level of the lesion or below (Fig. 10 A).

$N G F$. NGF mRNA in situ hybridization signals could not be detected in normal adult spinal cord (Fig. $11 A$ ), correlating well with previous findings (Korsching and Thoenen, 1985). With use of RPA, weak signals were found (Fig. 10B). After injury, weightdrop as well as transection, meningeal cells and some Schwann cells of nerve roots exhibited strong NGF mRNA signals (Fig. $11 B, G)$. Positively labeled cells were primarily found in arachnoidea and seen $6 \mathrm{hr}, 1 \mathrm{~d}$, and $3 \mathrm{~d}$ after injury, peaking at $1 \mathrm{~d}$. RPAs confirmed the in situ hybridization findings, with upregulated levels of NGF mRNA $1 \mathrm{~d}$, but not 6 weeks, after injury (Figs. 9E, 10B). At the neonatal stage, neurons of the lateral horn presented moderate levels of NGF mRNA (Fig. 12A,D), and an area located centrally, close to the midline, presented low levels. Meningeal cells and white matter were devoid of significant signals (Fig. 12A,D). After injury of the newborn spinal cord, strong NGF mRNA signals were found in the meningeal cells around the site of the lesion (Fig. 12B,C,H,I). Most positively labeled cells resided in arachnoidea. Strong NGF mRNA labeling in the meningeal cells was detected $6 \mathrm{hr}, 12 \mathrm{hr}$, and $1 \mathrm{~d}$ after injury (Fig. 9G). Significant increases were also detected by RPA quantification (Fig. 9F, 10A). No robust alterations of NGF mRNA signals could be detected in gray or white matter above or below the lesion (Figs. 9H, 12E,F).

NT3. NT3 mRNA hybridization signals could not be detected by in situ hybridization of either normal or injured adult spinal cord. In good agreement with previous findings (Ernfors and Persson, 1991; Ernfors et al., 1992), the neonatal spinal cord exhibited moderate NT3 expression signals in cells of the ventral horn (data not shown). RPAs did not detect any statistically significant alterations of NT3 mRNA after SCI (Figs. 9J, 10A, $B$ ).

NT4. NT4 mRNA hybridization signals could not be detected by in situ hybridization of either adult or neonatal spinal cord tissue. Measured by RPA, only very low NT4 mRNA levels were detected in adult and neonatal spinal cord (Fig. 10 $A, B$ ), which is in agreement with previous findings (Timmusk et al., 1993). No statistically significant alterations of NT4 mRNA after SCI could be detected by RPAs.

\section{GDNF family ligands and related receptors}

$R E T$. RET mRNA expression was observed in motoneurons of normal adult (Fig. 6 $A$ ) and neonatal spinal cord and a subpopulation of dorsal root ganglia cells (Fig. $7 E$ ), in agreement with previous findings (Nosrat et al., 1997a; Golden et al., 1999; Leitner et al., 1999; Widenfalk et al., 1999). No change of RET mRNA levels could be detected after injury.

$G F R \alpha-1$. GFR $\alpha-1$ mRNA signals were found in most neurons

\section{$\leftarrow$}

expression is markedly increased in cells of degenerated fiber tracts, such as the ascending sensory tract in the dorsal funiculus above the lesion $(C)$, and the descending corticospinal tract below the lesion in the dorsal funiculus $(I)$. $J$, Horizontal section of a spinal cord 6 weeks after complete transection. Cells strongly positive for the truncated TrkB probe are found in both gray and white matter tissue but not in the glial scar separating the rostral and caudal stumps. Ependymal cells of the central canal are also strongly positive, as seen in the rostral stump (left) along the midline and reaching the glial scar in the middle. $K$, Bright-field photomicrograph showing strong truncated TrkB mRNA signals in a subpopulation of cells in the lateral funiculus of lumbar white matter 6 weeks after the operation. $L$, Neurons close to the lesion $1 \mathrm{~d}$ after injury labeled by p75 mRNA hybridization. Scale bar (shown in $A$ ): $A-I, 1 \mathrm{~mm} ; J, 300 \mu \mathrm{m} ; K, L, 25 \mu \mathrm{m}$. 


\section{$R P A$}
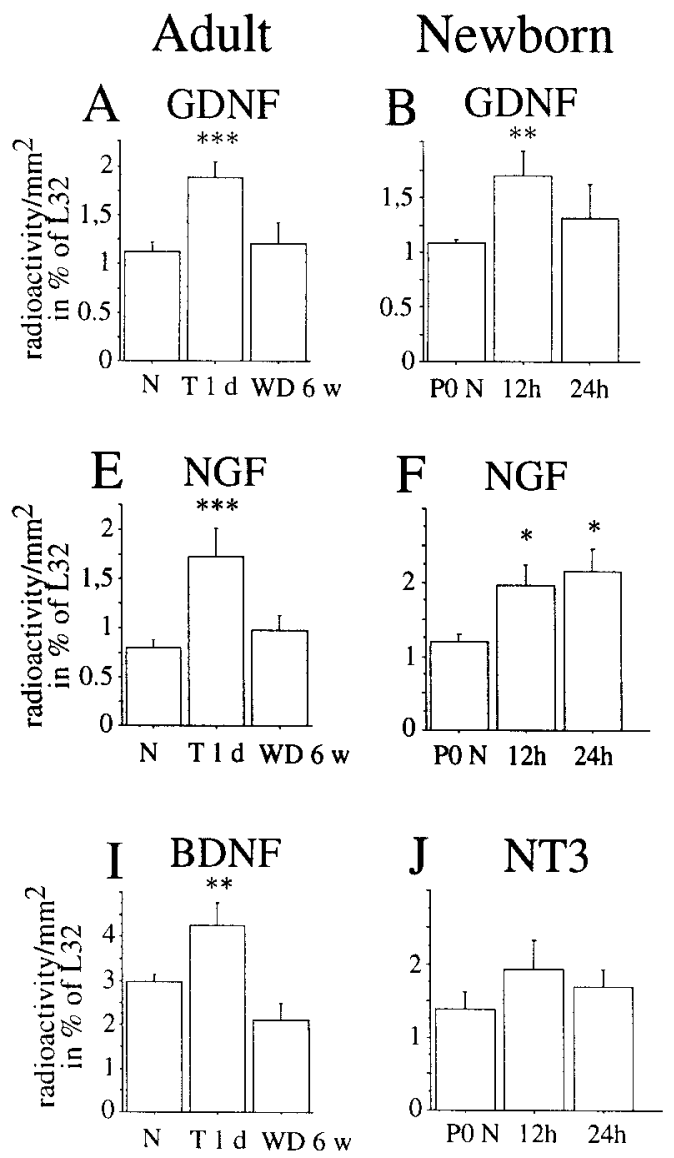

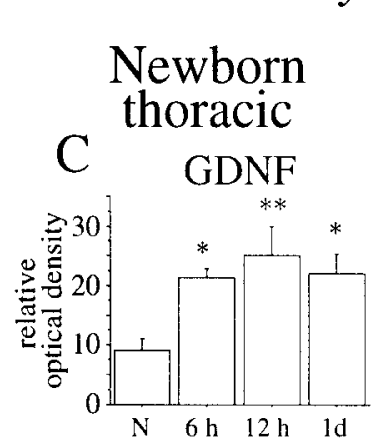

In situ hybridization
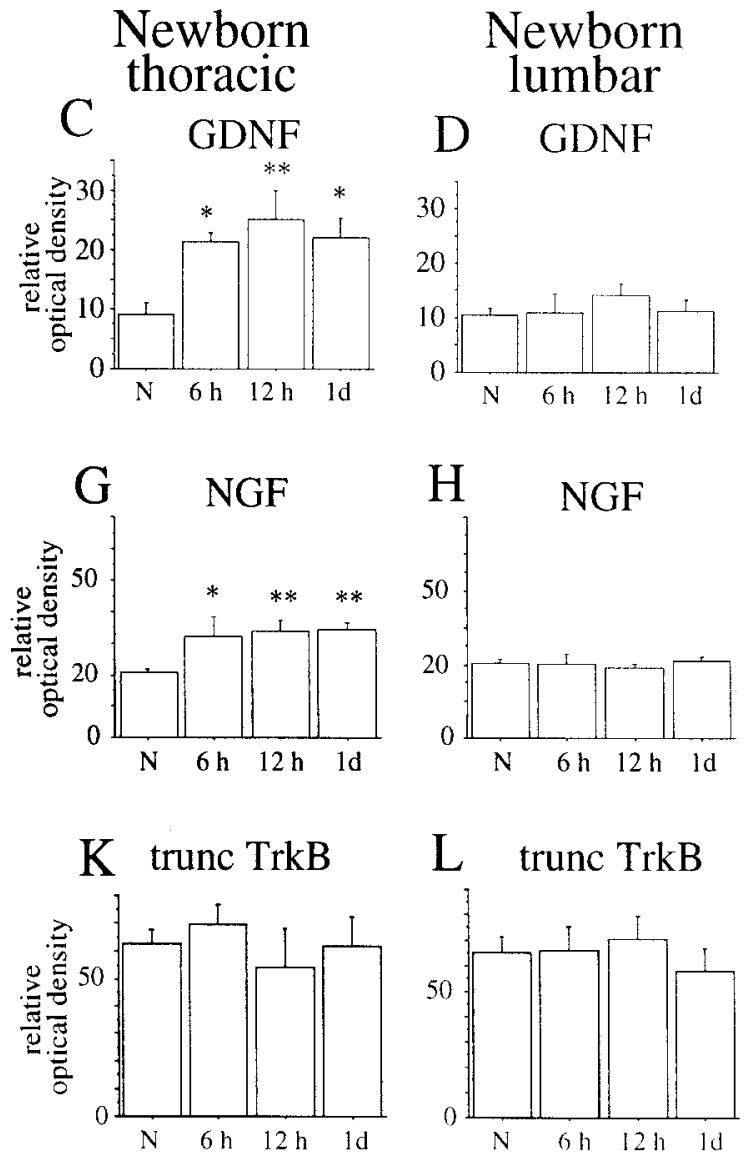

Figure 9. Regulation of different mRNA species after SCI measured by RPA $(A, B, E, F, I, J)$ and in situ hybridization $(C, D, G, H, K, L)$. Bars in RPA graphs represent average radioactivity per area (detected by phosphoimaging) expressed in arbitrary units and displayed as percentage of the housekeeping gene L32. $A$, GDNF mRNA was increased at the level of injury $1 \mathrm{~d}$ after transection ( $T$ ), but not 6 weeks after weight-drop (WD) injury $\left(F_{(2,30)}=8 ; p<0.01\right)$. B, GDNF mRNA expression levels were significantly elevated at the level of injury $1 \mathrm{~d}$ after partial transection of the neonatal spinal cord measured by RPA $\left(F_{(2,15)}=4.3 ; p<0.05\right)$. $C$, Quantification of in situ hybridization demonstrated increased GDNF mRNA expression at the level of the injury, $6 \mathrm{hr}, 12 \mathrm{hr}$, and $1 \mathrm{~d}$ after injury. $D$, No significant difference in GDNF mRNA expression could be found at the lumbar level. $E$, NGF mRNA probe signals were upregulated $1 \mathrm{~d}$ after transection, but not 6 weeks after weight-drop injury $\left(F_{(2,30)}=11 ; p<0.001\right)$. $F$, NGF mRNA expression levels were significantly elevated at the level of injury $12 \mathrm{hr}$ and $1 \mathrm{~d}$ after partial transection of neonatal spinal cord $\left(F_{(2,15)}=4.3 ; p<0.05\right)$. $G$, NGF mRNA expression increased at the thoracic level $6 \mathrm{hr}, 12 \mathrm{hr}$, and $1 \mathrm{~d}$ after injury. $H$, No significant difference in NGF mRNA expression could be found at the lumbar level. $I$, BDNF mRNA probe signals were upregulated $1 \mathrm{~d}$ after transection but not 6 weeks after weight-drop injury $\left(F_{(2,30)}=\right.$ $9 ; p<0.001) . J$, No statistically significant differences in NT3 mRNA expression were found after injury. $K$, No statistically significant differences were found in truncated TrkB mRNA expression at the thoracic level after injury. $L$, Likewise, no statistically significant differences were found in truncated TrkB mRNA expression at the lumbar level.

of the spinal cord gray matter and a subpopulation of dorsal root ganglia cells in adults as well as newborns (Figs. 6C, 7A). Motoneurons in the ventral horn were strongly positive. These findings were in agreement with previous studies (Nosrat et al., 1997a; Golden et al., 1999; Leitner et al., 1999). Beginning 1 d after injury, GFR $\alpha-1$ mRNA levels were upregulated in dorsal roots at the lesion level. Three days after injury, weak GFR $\alpha-1$ mRNA signals were found in glial cells close to the lesion. In adult spinal cord 6 weeks after impact injury, a few cells of the scar tissue were GFR $\alpha-1$ mRNA positive, suggesting that they might be Schwann cells. In addition, moderate GFR $\alpha-1$ mRNA hybridization signals were found in degenerating white matter, presumably in astrocytes (Figs. $3 C, H, M, 13 A$ ). There was no statistically significant increase in gray matter tissue.

The GFR $\alpha-1$ antibody was tested on P0 rat kidney, and GFR $\alpha-1$ immunoreactivity correlated well with previous studies of GFR $\alpha-1$
mRNA expression in P0 kidney (Nosrat et al., 1997a; Golden et al., 1999). In the spinal cord, the most prominent GFR $\alpha-1$ immunoreactivity was found in lamina II of the dorsal horn, labeling axon terminals of sensory neurons. The rest of the spinal cord gray matter was only weakly labeled (Fig. 13B). In dorsal root ganglia, a subpopulation of neurons was GFR $\alpha-1$ positive, correlating well with previous studies of GFR $\alpha-1$ mRNA (Bennett et al., 1998). The most striking difference 1 and 6 weeks after injury was an increased GFR $\alpha-1$ immunoreactivity in nerve roots at the level of the lesion (Figs. 13D, 14A). Six weeks after injury an increased GFR $\alpha-1$ immunolabeling was found in degenerating fiber tracts of the spinal cord white matter (Figs. $13 E, F, 14 B$ ), correlating well with in situ hybridization data. No specific GFR $\alpha$ - 1 immunostaining could be found in nondegenerating white matter. Additionally, a few cells in the scar tissue 6 weeks after injury were moderately labeled. Six months after injury the GFR $\alpha-1$ immunostaining of 


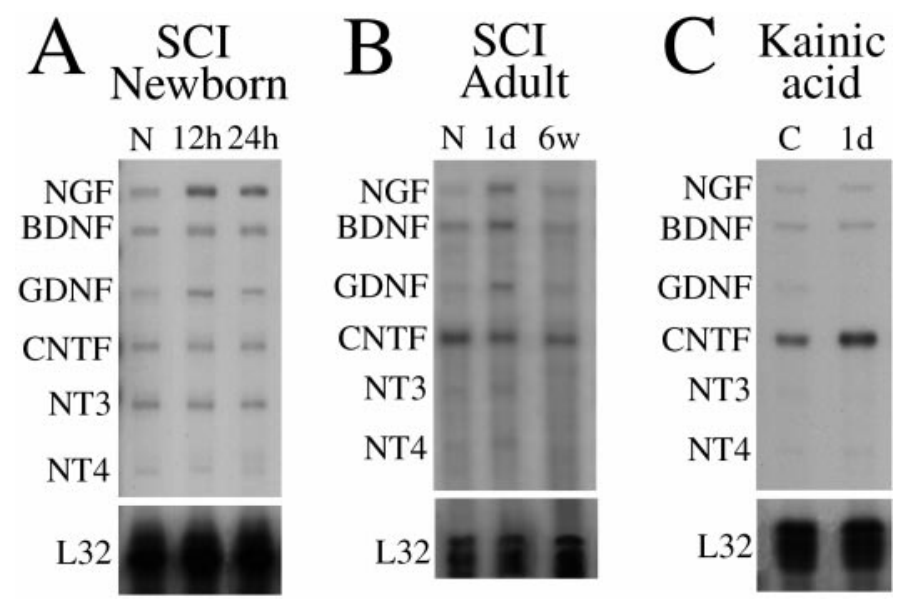

Figure 10. Neurotrophic factor expression in intact and injured adult and neonatal spinal cord. Representative autoradiograms from RPAs are shown. A riboprobe complementary to the housekeeping gene L32 was used as an internal standard. $A$, At the newborn stage, NGF and GDNF mRNA signals increased. $B$, GDNF, NGF, and BDNF signals were upregulated $1 \mathrm{~d}$ after transection in adults. $C$, CNTF mRNA levels were upregulated $1 \mathrm{~d}$ after kainic acid delivery.

degenerated white matter still persisted but had become somewhat weaker.

GFR $\alpha$-2 mRNA expression was detected in adults as weak labeling of laminas I, III, and IV of the dorsal horns and strong hybridization signals in a subpopulation of dorsal root ganglia cells (Fig. 6E). The spinal cords of uninjured newborn animals exhibited a weak GFR $\alpha-2$ mRNA hybridization labeling throughout the gray matter and in a subpopulation of dorsal root ganglia cells (Fig. 7C). Expression patterns were in agreement with previous findings (Widenfalk et al., 1997; Golden et al., 1999; Leitner et al., 1999). SCI led to no robust alteration in GFR $\alpha-2$ mRNA expression in either adult or newborn rats.

GDNF. GDNF mRNA hybridization signals could not be detected by in situ hybridization in normal adult spinal cord (Fig. $11 C, E)$. After injury strong upregulation of GDNF mRNA occurred in the meninges (Fig. 11E,H) and Schwann cells of nerve roots $($ Fig. $11 F$ ). The time course of this increased expression resembled that for NGF, starting 2 hr after injury and continuing up to $3 \mathrm{~d}$ after injury. Analyses with RPA demonstrated increased GDNF mRNA levels $1 \mathrm{~d}$, but not 6 weeks, after injury (Figs. $9 A$, $10 B)$.

In neonatal spinal cord, strong GDNF mRNA signals were found in cells located dorsolateral to the central canal, presumably Clark's nucleus (thoracic nucleus), and weak signals were noted in the dorsal horns (Fig. 15A,D), as reported previously (Nosrat et al., 1996; Widenfalk et al., 1999). After partial transection of neonatal spinal cord, a marked upregulation was seen in meningeal cells in the lesion vicinity (Fig. $15 B, C, I$ ). Similar to the upregulation of NGF mRNA, most GDNF-positive cells were found in the arachnoid. GDNF mRNA in situ hybridization signals were upregulated $6 \mathrm{hr}, 12 \mathrm{hr}$, and $1 \mathrm{~d}$ after injury (Fig. 9C). No robust alteration could be found in gray or white matter of the spinal cord below the lesion (Figs. 9D, 15E,F). RPAs revealed that the upregulation was statistically significant $12 \mathrm{hr}$ after the operation (Figs. 9B, 10A).

NTN and PSP. No NTN or PSP mRNA could be detected by in situ hybridization at any stage investigated.

$C N T F$. CNTF mRNA levels were quantified using only RPAs,

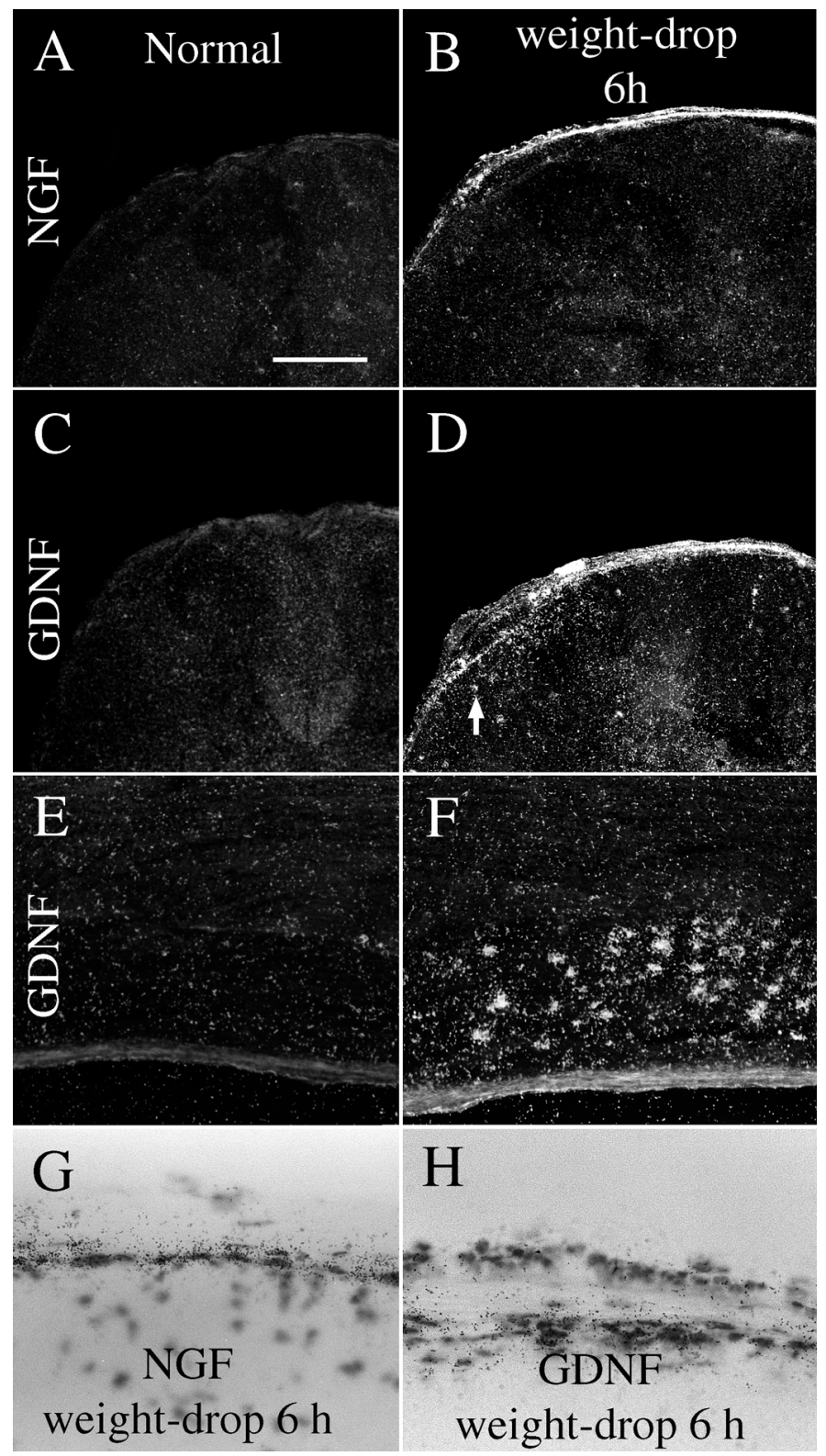

Figure 11. GDNF and NGF mRNA expression is increased after injury of the adult spinal cord. $A$, No robust NGF mRNA signals were found in normal uninjured spinal cord. $B$, Six hours after weight-drop injury, strong NGF mRNA signals were found in meningeal and Schwann cells close to the lesion. $C$, In normal adult spinal cord, no robust GDNF mRNA expression could be detected. $D$, Six hours after weight-drop injury, a marked upregulation of GDNF mRNA signals was found in meningeal and Schwann cells at the level of the lesion. Weak GDNF mRNA signals were observed in glial cells, presumably astrocytes, in the immediate lesion vicinity (arrow). E, Horizontal section of a thoracic dorsal root in a normal animal. No specific GDNF mRNA labeling is observable. $F$, Six hours after weight-drop injury, intense GDNF mRNA labeling was found in dorsal root Schwann cells at the lesion level. $G$, Bright-field images depicting meningeal cells expressing NGF mRNA $6 \mathrm{hr}$ after injury. $H$, GDNF mRNA signals in cells of the dorsal meninges $6 \mathrm{hr}$ after injury. Scale bar (shown in $A$ ): A-D, $400 \mu \mathrm{m} ; E, F, 250 \mu \mathrm{m} ; G, H, 60 \mu \mathrm{m}$.

revealing high levels of CNTF mRNA expression in normal adult spinal cord compared with the other neurotrophic factors investigated (Fig. 10B). Somewhat lower levels were detected at the newborn stage (Fig. 10A). No statistically significant alterations after injury were found. 


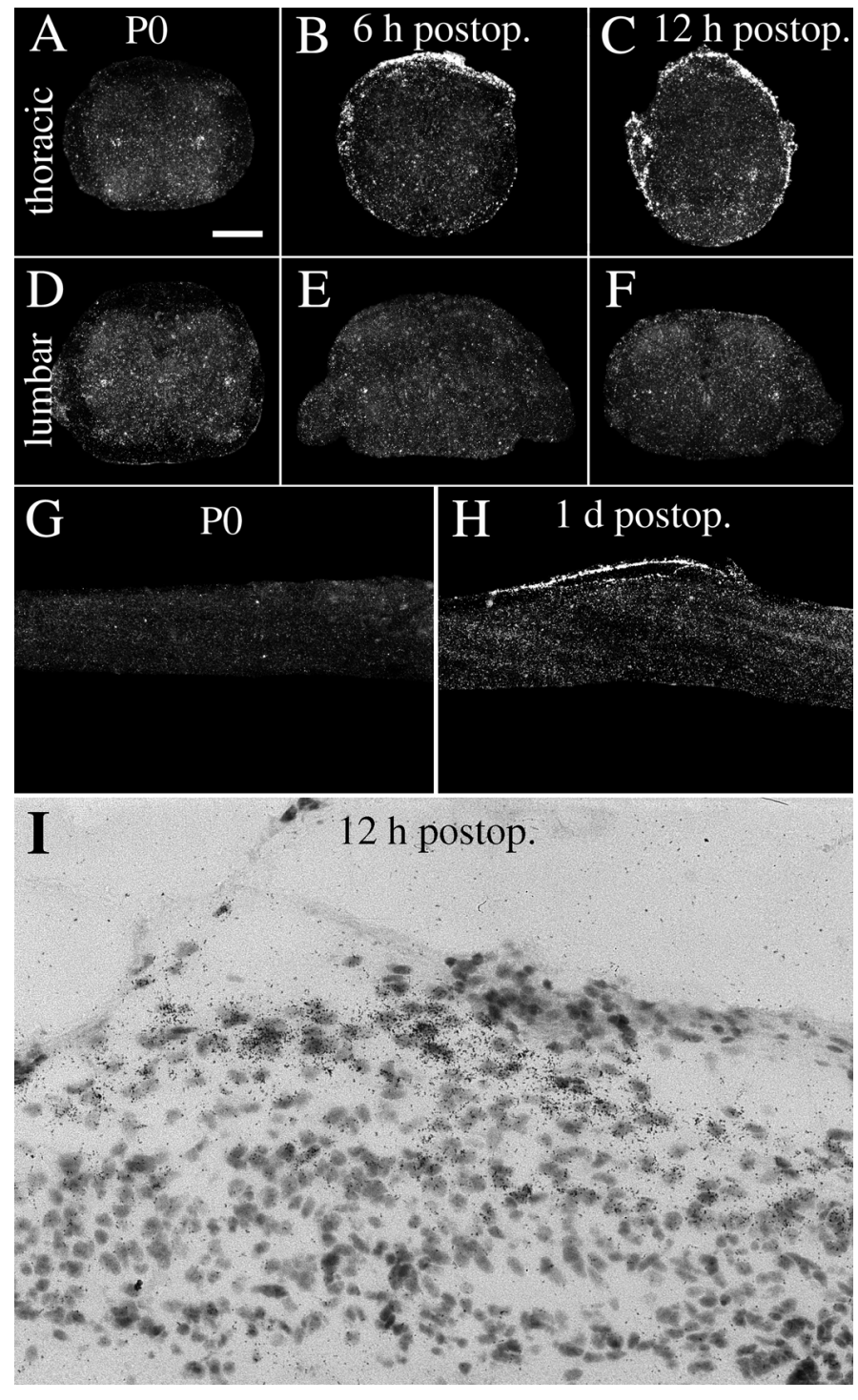

Figure 12. NGF mRNA hybridization signals increase after partial transection injury to the neonatal spinal cord. $A, D$, NGF mRNA expression in normal uninjured neonatal $(P O)$ spinal cord is present in cells of the gray matter lateral horn $(A, D) . B, C, E, F$, Six and $12 \mathrm{hr}$ after injury, NGF mRNA synthesis is markedly increased in meningeal cells around the lesion. Schwann cells of dorsal roots on the transected side (left side) also exhibit strong NGF mRNA signals, whereas the dorsal roots of the opposite side are devoid of signal or only weakly positive $(B, C)$. At lumbar levels no altered expression of NGF mRNA could be found $(E, F)$. $G$, Sagittal section of normal uninjured neonatal spinal cord. No robust NGF mRNA signals are seen in meningeal cells. $H$, Sagittal section of neonatal spinal cord $1 \mathrm{~d}$ after injury exhibiting strong NGF mRNA expression in meningeal cells close to the lesion. I, Bright-field view depicting NGF probe-labeled meningeal cells close to the lesion. Scale bar (shown in $A$ ): $A-F, 250 \mu \mathrm{m} ; G, H, 400 \mu \mathrm{m} ; I, 40 \mu \mathrm{m}$.

\section{Effects of kainic acid}

The immediate-early gene c-fos was upregulated in a restricted subpopulation of neurons of the spinal cord gray matter $4 \mathrm{hr}$ after treatment (Figs. 2E, F, 16A). Scattered labeled neurons $4 \mathrm{hr}$ after treatment were found in laminas II-IX, with strongest signals noted in laminas III-VII. One day after treatment moderate c-fos mRNA hybridization signals were found in layers III-IV and VI-VII, and possibly in a few cells in laminas I, II, and V. Three and seven days after kainic acid delivery, no or few neurons were c-fos positive. Upregulation of c-fos was less dramatic, however, in the spinal cord than in the brain (Fig. $2 C, D$ ). Upregulations of neurotrophic factor mRNA levels, including BDNF, GDNF, and RET mRNA, were found in the hippocampal formation as described previously (Wetmore and Olson, 1993; Schmidt-Kastner et al., 1994; Trupp et al., 1997) (data not shown).

The number of BDNF mRNA hybridization signal-positive neurons in the spinal cord increased $4 \mathrm{hr}$ after kainic acid delivery (Fig. 16C). Positively labeled cells in kainic acid-treated animals were found in Rexed's laminas IV, V, and VII (possibly also in VI). RPA revealed a nonsignificant trend of increased BDNF mRNA at $4 \mathrm{hr}$. CNTF, as demonstrated by RPA analyses, increased slightly $1 \mathrm{~d}$ after kainic acid delivery (Figs. 10C, 16D). No other alteration of investigated mRNA species was found, as exemplified in Figure $16 B$ by truncated TrkB.

\section{DISCUSSION}

We demonstrate in the present study the expression patterns of 15 gene products, including all members of the NGF family, all NGF family receptors, three members of the GDNF family, and three of the receptors, as well as CNTF in the normal and injured newborn and adult spinal cord. The different upregulations observed are depicted schematically in Figure 17. Perhaps unexpectedly, NGF and GDNF were primarily upregulated in meningeal cells after mechanical spinal cord injury. Schwann cells in nerve roots also exhibited strong NGF and GDNF mRNA signals in response to injury. No increase in levels of neurotrophic factors, such as NGF, NT3, NT4, or GDNF at lumbar levels (target areas for several important descending fiber tracts) could be detected in either newborn or adult spinal cord. BDNF mRNA increased slightly in neurons after SCI, and BDNF and CNTF mRNA levels were slightly elevated after kainic acid delivery. Upregulations of neurotrophic factor receptors after mechanical SCI were limited to $\mathrm{p} 75$, truncated $\operatorname{TrkB}$, and $\operatorname{GFR} \alpha-1$. Truncated TrkB and GFR $\alpha-1$ mRNA increased in glial cells, presumably reactive astrocytes in degenerating fiber tracts; p75 increased in neurons. No robust mRNA expression for any of the neurotrophic factor ligands or receptors could be detected in oligodendrocytes. The upregulations of different factors and receptors typically followed either of two time frames. One occurred rapidly, peaking within a day or two, and did not last more than a week. The other, typified by truncated TrkB and GFR $\alpha-1$, occurred slowly, peaking within months and lasting throughout the studied time (Fig. 17).

Several reports have described the use of neurotrophic factors as experimental therapies in models of spinal cord injury, reporting improved regeneration and cell survival (Schnell, 1994; Novikova et al., 1996; Tuszynski et al., 1996; Grill et al., 1997; Kobayashi et al., 1997; Houweling et al., 1998; Menei et al., 1998; Blesch et al., 1999; Liu et al., 1999). In view of this and the presence of several different neurotrophic factor receptors in the spinal cord, it is perhaps surprising that spinal cord tissue does not upregulate production of factors such as BDNF and NT3 more readily. The possible roles of the different responses are discussed below.

\section{Rapid transient increases of local NGF and GDNF mRNA levels after $\mathrm{SCl}$}

NGF and GDNF were upregulated in meningeal cells after injury. A possible role for NGF and GDNF relates to scar formation after CNS injury. Meningeal cells proliferate and invade the injured CNS and constitute a major cellular component of the glial scar that results from weight-drop injury of the spinal 

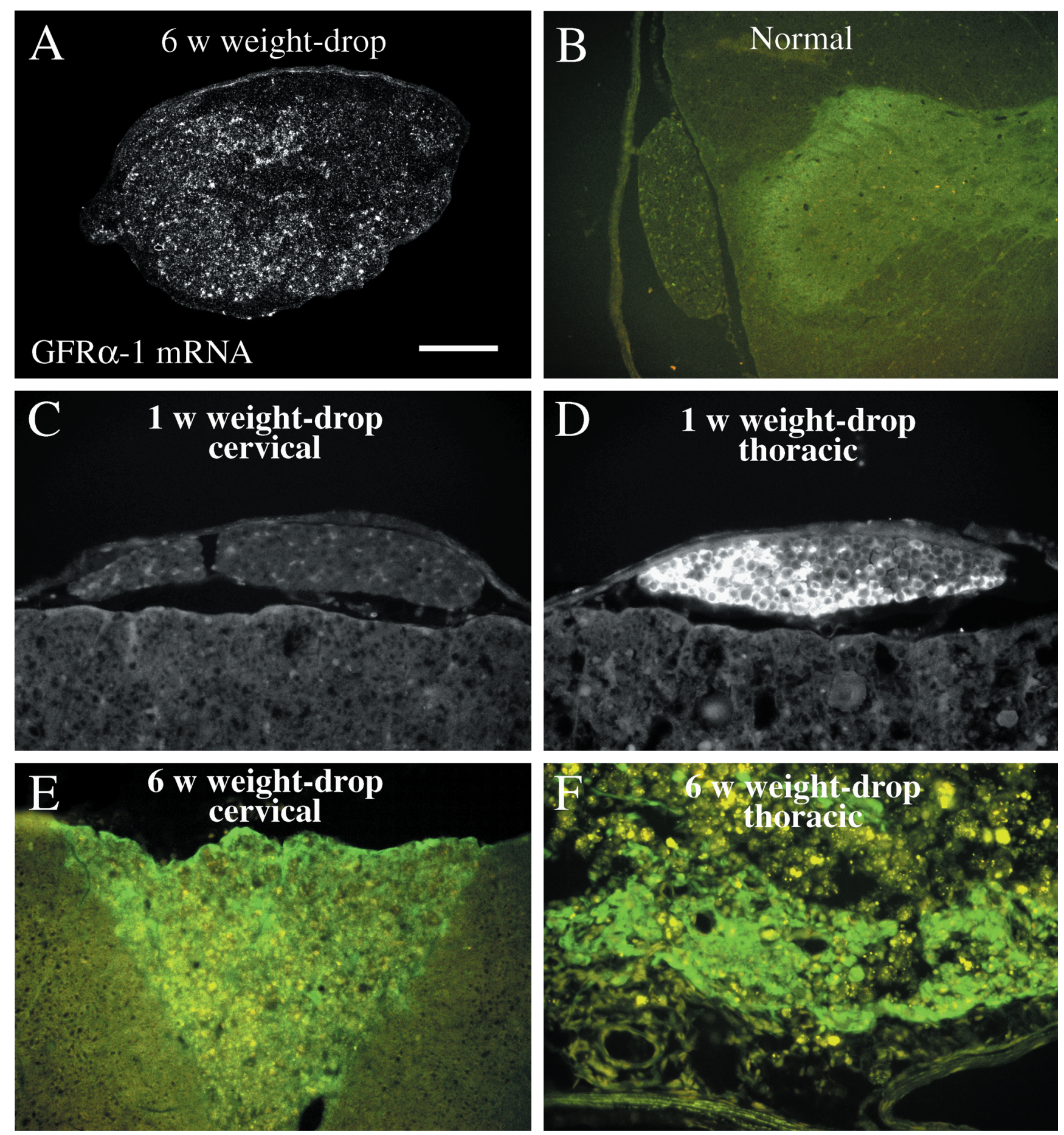

Figure 13. GFR $\alpha-1$ protein immunoreactivity is increased in nerve roots and degenerating white matter after SCI. $A$, Dark-field photomicrograph depicting GFR $\alpha$ - 1 in situ hybridization signals in degenerating white matter, close to the lesion, 6 weeks after weight-drop. $B$, GFR $\alpha$ - 1 immunostaining in a dorsal horn and nerve root in a normal animal. Robust immunoreactivity is seen in lamina II of the dorsal horn. Other laminas of the gray matter are weakly positive, and in the nerve root the GFR $\alpha-1$ antibody labels some nerve fibers and possibly weakly Schwann cells. $C$, GFR $\alpha-1$ immunoreactivity in a cervical dorsal root 6 weeks after weight-drop injury. Some nerve fibers are positive, and a weak staining is possibly also present in Schwann cells. $D$, One week after injury a dramatic increase in GFR $\alpha-1$ immunoreactivity is seen in Schwann cells of a dorsal root immediately caudal to the weight-drop site (thoracic level). Meningeal cells are also GFR $\alpha-1$ positive. $E$, Increased GFR $\alpha-1$ immunoreactivity ( green fluorescence), was found in degenerating white matter of the ascending fiber tract in the dorsal funiculus 6 weeks after weight-drop injury. Autofluorescence in infiltrating immune cells (orange-yellow fluorescence) is also seen. Note that no robust immunolabeling is seen in the white matter adjacent to the ascending portion of the dorsal funiculus. $F$, Six weeks after injury, robust GFR $\alpha-1$ antibody immunoreactivity ( green) is observed in the remaining white matter at the level of injury. Numerous immune cells/phagocytes are present, displaying an orange-yellow autofluorescence. Scale bar (shown in $A$ ): $A, 200 \mu \mathrm{m} ; B, 400 \mu \mathrm{m} ; C-F$, $100 \mu \mathrm{m}$. 

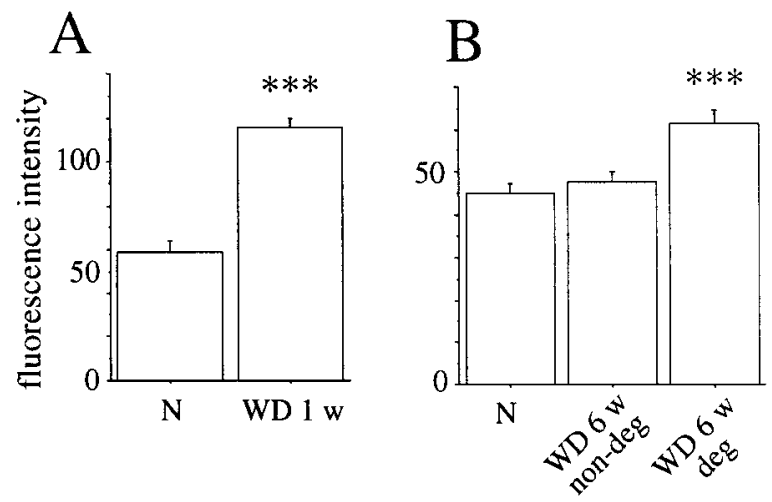

Figure 14. GFR $\alpha-1$ protein levels increase in injured nerve roots and degenerating white matter of the spinal cord. $A$, The intensity of GFR $\alpha-1$ immunoreactivity in thoracic nerve roots in normal animals $(N)$ and animals subjected to SCI 1 week earlier (WD 1 w). A marked increase is observed in injured nerve roots (unpaired $t$ test; $\mathrm{df}=14 ; t=8.6 ; p<$ 0.001). $B$, An increase in GFR $\alpha-1$ protein levels was also found in degenerating white matter of the spinal cord 6 weeks after injury (ANOVA; $\left.F_{(2,21)}=11 ; p<0.001\right)$. Measurements were performed in intact white matter in normal animals $(N)$, in nondegenerated white matter in the dorsal funiculus at the cervical level 6 weeks after injury (WD 6 w non-deg), and in degenerated white matter in the dorsal funiculus at the cervical level 6 weeks after injury (WD $6 \mathrm{w} \mathrm{deg}$ ).

cord (J. Widenfalk, A. Lipson, M. Jubran, C. Hofstetter, T. Ebendal, Y. Cao, and L. Olson, unpublished observations). NGF has been shown to induce process outgrowth but not stimulate proliferation of meningeal cells in vitro (Frisén et al., 1998), and meningeal cells of the glial scar in spinal cord lesions express $\mathrm{p} 75$, TrkA, GFR $\alpha$-1, and TrkB (Frisén et al., 1992; Risling et al., 1992; this study). NGF and GDNF secreted from meningeal cells additionally may have effects on neurons, including rescue from cell death (Henderson et al., 1994) and induction of neurite outgrowth (Tuszynski et al., 1996). However, the opposite effect has also been shown for NGF: induction of apoptosis in cells expressing p75 but not TrkA (Dechant and Barde, 1997), an expression pattern that is present, in fact, in most neurons close to the lesion. Hypothetically, increased levels of NGF and GDNF at the lesion site could also arrest axon regeneration by providing injured axons with sufficient local trophic signals to initiate terminal arborization at the level of the lesion.

\section{Increased neuronal BDNF and p75 mRNA levels after $\mathbf{S C I}$}

Upregulations of p75 mRNA after SCI described by Reynolds and colleagues (1991) were confirmed. However, the p75 mRNA signals were confined to neurons, and we could find no specific association of the p75-positive cells with blood vessels. Neurons positive for p75 mRNA were found at cervical, thoracic, and lumbar levels, in particular close to the lesion. The p75 mRNA upregulation occurred acutely after injury, presumably in axotomized neurons and neurons endangered by secondary degeneration around the lesion. The NGF low-affinity receptor p75 may increase the neuronal sensitivity to NGF (Davies et al., 1993; Rydén et al., 1997) or induce cell death in cells lacking TrkA receptor (Dechant and Barde, 1997). Interestingly, no robust p75 mRNA upregulation occurred in pyramidal layer $\mathrm{V}$ hindlimb motor cortex after injury (data not shown). Hence, upper motoneurons do not upregulate p75 as lower motoneurons do after axotomy (Ernfors et al., 1989). Corticospinal neurons survive axotomy at the spinal cord level in adulthood (McBride et al.,
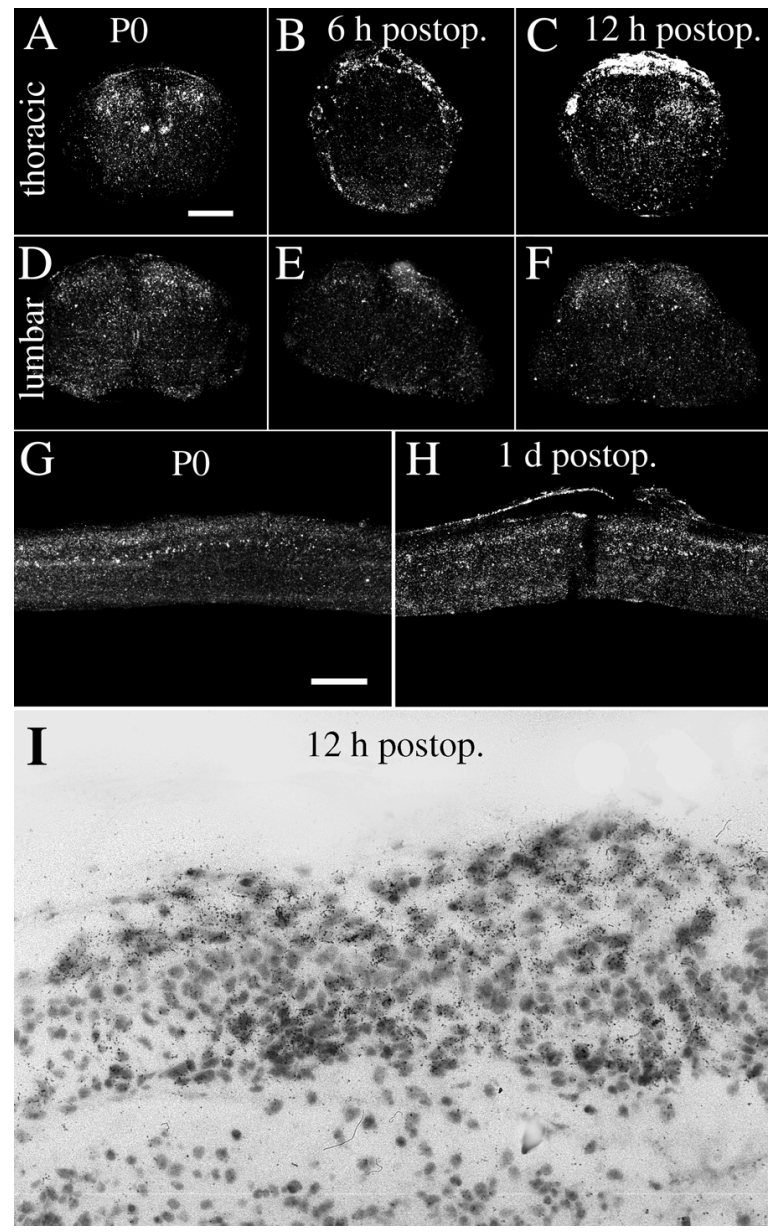

Figure 15. GDNF mRNA hybridization signals increase after partial transection injury to the neonatal spinal cord. $A, D$, Normal uninjured neonatal $(P 0)$ spinal cord exhibits strong GDNF mRNA signals in cells of Clark's column $(A)$ and weak signals in the dorsal horns. $B, C, E, F$, Six and $12 \mathrm{hr}$ after injury, a robust increase of GDNF mRNA signals is seen in meningeal cells around the lesion. Schwann cells of dorsal roots on the transected (left) side also exhibit strong GDNF mRNA signals (especially in $C$ ), whereas the dorsal roots of the opposite side are devoid of signal or are only weakly positive $(B, C)$. At lumbar levels no altered expression of GDNF mRNA could be found $(E, F)$. $G$, Sagittal section of normal uninjured neonatal spinal cord. GDNF mRNA expression is seen in Clark's column and in the dorsal horn. $H$, Sagittal section of neonatal spinal cord $1 \mathrm{~d}$ after injury with strong GDNF mRNA expression in meningeal cells close to the lesion. I, Bright-field photomicrograph depicting GDNF probe-labeled cells in meningeal cells close to the lesion. Scale bar (shown in $A$ ): $A-F, 250 \mu \mathrm{m} ; G, H, 400 \mu \mathrm{m} ; I, 40 \mu \mathrm{m}$.

1989; Merline and Kalil, 1990), and lower motoneurons survive distal peripheral axotomy in adulthood (Lowrie and Vrbova, 1992). This suggests an involvement of p75 in the successful regeneration of lower motoneurons rather than in mediating apoptosis, despite lack of the TrkA receptor.

The neuronal upregulations of BDNF mRNA in adults, primarily adjacent to the lesion but also in a few neurons at some distance from the lesion, were the only signs of increased synthesis of target-derived neurotrophic factors. At a distance from the lesion, however, the number of neurons specifically expressing BDNF mRNA was very low (Fig. $3 D, N$ ). The upregulation occurred to some extent (laminas IV and V) where a moderate amount of corticospinal fiber termination has been shown in the spinal cord (laminas III-VI) (Casale et al., 1988; Brösamle and 
A cFOS

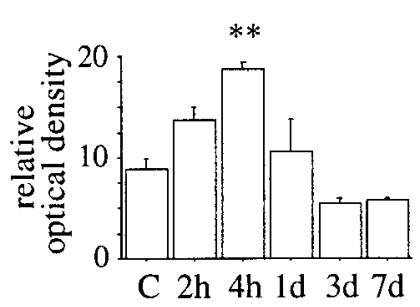

B trunc TrkB
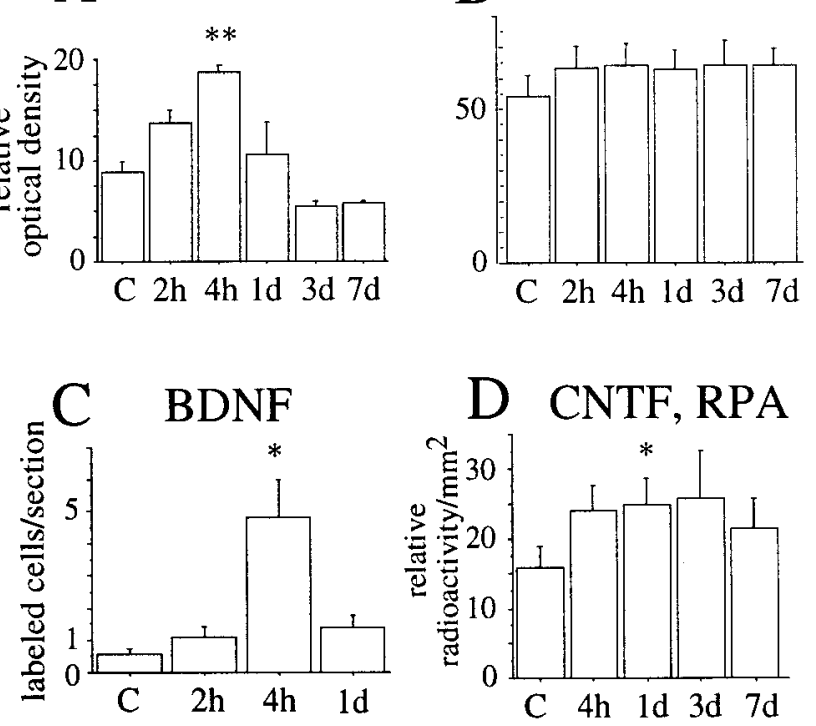

Figure 16. Regulation of different mRNA species in lumbar spinal cord after kainic acid injection. Data were obtained from in situ hybridization $(A-C)$ and RPA $(D)$. A, Quantification of in situ hybridization signals for c-fos on x-ray film at different time points after kainic acid delivery. Compared with controls (Ringer's solution injected, designated $C$ ), c-fos increased gradually, peaking at $4 \mathrm{hr}\left(F_{(3,18)}=5.4 ; p<0.01\right)$. $B$, No robust changes were found in truncated TrkB mRNA expression. $C$, The number of BDNF mRNA-labeled cells per section increased $4 \mathrm{hr}$ after treatment $\left(F_{(3,25)}=17.3 ; p<0.001\right)$. D, CNTF mRNA levels measured by RPA were significantly increased $1 \mathrm{~d}$ after kainic acid delivery $\left(F_{(3,30)}=4.3\right.$; $p<0.05$ ). Bars represent average radioactivity per area (detected by phosphoimaging) expressed as percentage of L32 values.

Schwab, 1997). No BDNF mRNA-positive cells were found where the most dense corticospinal tract termination is localized. Still, some trophic actions, although not very dramatic, on the BDNF-sensitive corticospinal (Giehl and Tetzlaff, 1996) and rubrospinal neurons (Tetzlaff et al., 1994; Kobayashi et al., 1997; Liu et al., 1999) may have taken place near the lesion. Some BDNF mRNA probe-labeled cells were located in laminas similar to those of p75-positive cells. Hence some neurons may possibly respond to injury by expressing both BDNF and p75. Because the TrkB receptor is expressed in virtually all spinal cord gray matter neurons, BDNF may help neurons survive via autocrine or paracrine routes. The dramatic glial upregulation of BDNF and NT3 mRNA expression close to the lesion shortly after SCI reported previously (Hayashi et al., 2000) were not observed in the present study by RPA or in situ hybridization.

\section{Slow increase of GFR $\alpha-1$ and truncated TrkB levels in degenerating spinal cord white matter}

The increase of GFR $\alpha-1$ in degenerating white matter resembles the upregulation that occurred in Schwann cells of nerve roots after injury, although the increase in Schwann cells was much more rapid, and GFR $\alpha-1$ mRNA and protein levels were much higher. This may reflect the slow Wallerian degeneration in the CNS compared with the PNS (Bignami and Ralston, 1969; Cook and Wisniewski, 1973). However, 6 months after injury the GFR $\alpha-1$ immunoreactivity in degenerating white matter was still weak and not as high as in Schwann cells. An increased synthesis of GFR $\alpha-1$ in white matter tissue undergoing Wallerian degeneration may result in improved axon growth permissiveness. GFR $\alpha-1$ protein present on the surfaces of glial cells could bind

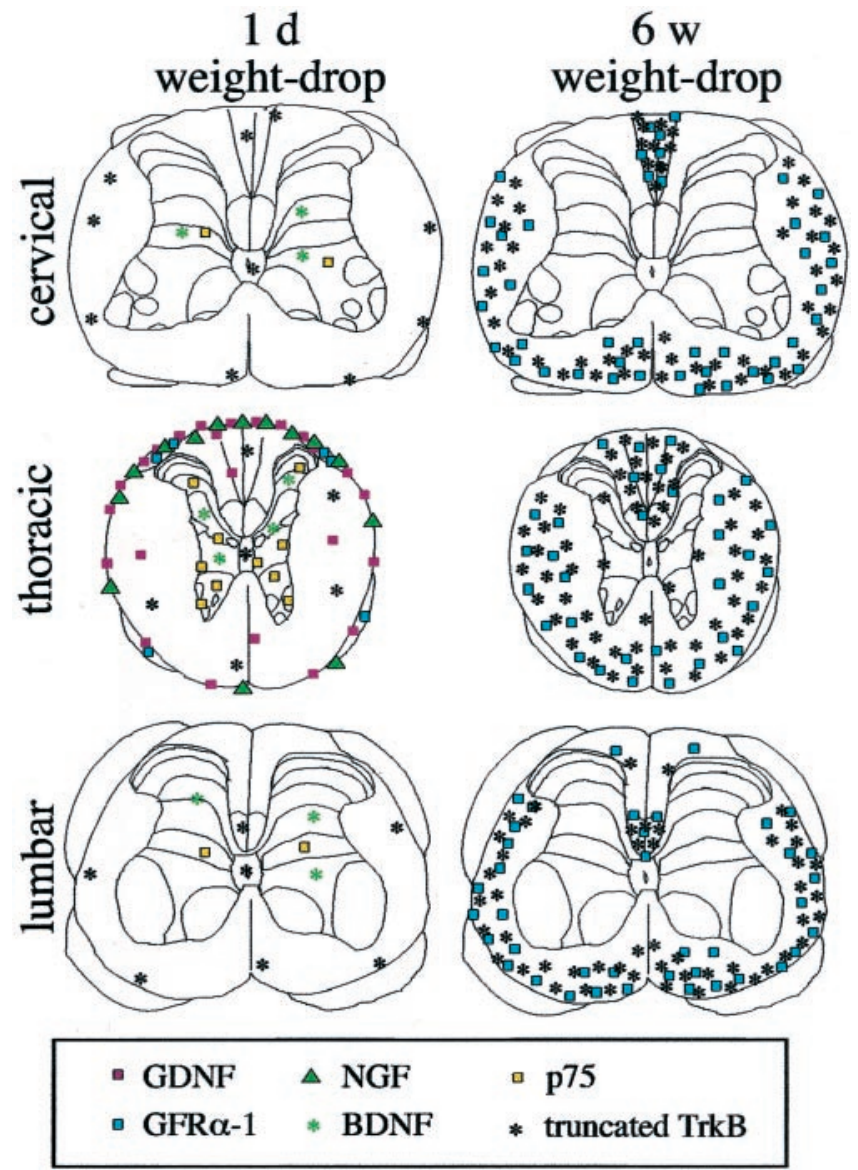

Figure 17. Schematic figure summarizing the upregulations of different neurotrophic factors and related receptors $1 \mathrm{~d}$ and 6 weeks after injury. Only elevated levels are shown. The number of symbols shown for each gene product correlates to the level of expression found. Rexed's laminas were drawn according to Paxinos and Watson (1986).

GDNF and the ligand-co-receptor complex in turn be presented to injured nerve fibers carrying the signal transducing protein RET, as has been hypothesized for Schwann cells and regenerating nerves in the PNS (Naveilhan et al., 1997; Trupp et al., 1997). However, we were unable to detect any robust expression of the potential ligands GDNF, NTN, or PSP in degenerating fiber tracts at a distance from the lesion, and neither the rubrospinal nor corticospinal neurons expressed RET mRNA (data not shown). Recently it was shown that GDNF may exert effects through GFR $\alpha-1$ independently of RET (Trupp et al., 1999), suggesting that GDNF or NTN may exert direct effects on astrocytes in degenerating white matter through $\operatorname{GFR} \alpha-1$. Previous findings of increased GFR $\alpha$ - 1 mRNA expression after excitotoxic treatment (Trupp et al., 1997), kindling or global forebrain ischemia (Kokaia et al., 1999), and aging (Bergman et al., 1999) demonstrated only neuronal expression.

The upregulation of truncated TrkB after weight-drop injury was not restricted to the level of the injury, as shown previously after a longitudinal dorsal funiculus cut (Frisén et al., 1992, 1993), but occurred throughout the spinal cord in degenerating fiber tracts. No robust truncated TrkB mRNA signals could be found in the cells of the scar tissue forming at the lesion center after either weight-drop or complete transection (Fig. $8 J$ ). The functional importance of a rich presence of truncated TrkB in degenerating white matter remains to be elucidated. One possibility is that 
truncated TrkB binds secreted BDNF and presents this to damaged neurons. However, the levels of BDNF mRNA in the spinal cord were quite low, especially 6 weeks after injury, when truncated TrkB mRNA levels were high. In this context, the possibility of anterogradely transported BDNF protein (Altar and DiStefano, 1998), for example in corticospinal tract fibers, could also be considered.

\section{Kainic acid delivery}

Glutamate toxicity may be involved in neurodegeneration after traumatic spinal cord lesions (Faden et al., 1988; Gomez-Pinilla et al., 1989; von Euler et al., 1994; Wrathall et al., 1994). Receptors for kainic acid are present in most neurons of the spinal cord gray matter (Martin et al., 1993; Sato et al., 1993), and delivery of kainic acid has been reported to lead to striking neuropathological changes in gray matter (Hugon et al., 1989) and motoneuron death (Pisharodi and Nauta, 1985). Excitotoxin delivery has been thoroughly studied in terms of effects on neurotrophic factor and receptor levels in the brain (Gall and Isackson, 1989; SchmidtKastner et al., 1994; Trupp et al., 1997, 1998). We used kainic acid as an alternative way to possibly induce neurotrophic factor upregulations in the spinal cord. Although strong upregulations of BDNF, GDNF, RET, and other neurotrophic molecules were found in the brain as expected, only minor changes of BDNF and CNTF were found in the spinal cord. For example, BDNF mRNA was upregulated in cortex layer $\mathrm{V}$ pyramidal neurons (data not shown) but was not detectable in spinal cord motoneurons. In addition, c-fos only increased in a subpopulation of neurons of spinal cord gray matter, compared with the massive increases that occurred in hippocampus and neocortex. These differences indicate an inability of the spinal cord neurons to upregulate neurotrophins or GDNF family members, but they may also suggest a higher tolerance to kainic acid in neurons of the spinal cord than those in the brain. It is also possible that the differences reflect differences in neuronal plasticity between brain and spinal cord (cf. Widenfalk et al., 1999b). In contrast to the study by Scarisbrick et al. (1999), we could not detect dramatic upregulations of BDNF or NT4 in glial cells after kainic acid treatment.

\section{Trophic support after injury of the neonate spinal cord and the PNS}

Partial transections of the spinal cord in neonates have been shown previously to alter the development of long fiber tracts such as the corticospinal tract (Bernstein and Stelzner, 1983). Because no robust increase in neurotrophic factor levels occurred at the lumbar level after a midthoracic lesion, any regeneration or rerouting of axons taking place after such injuries is unlikely to be attributable to synthesis of chemoattractant, target-derived neurotrophins or GDNF. An upregulation of neurotrophic factor production in postsynaptic neurons, in response to deafferentation, would seem a logical consequence of axotomy according to the general view of how neurotrophic factors act in a retrograde target-derived fashion (Thoenen, 1991). Apparently, at the sensitivity level of our methods, this is not the case in neonatal spinal cord for any of the investigated neurotrophic factors at the mRNA level. Except for small increases of BDNF mRNA, the picture was similar in the adult spinal cord. Schwann cells in the PNS readily increase their production of neurotrophic factors after injury and serve as an alternative source of trophic support (DiStefano and Curtis, 1994; Naveilhan et al., 1997). The oligodendrocytes responsible for the myelination of nerve fibers in the

\section{PNS}

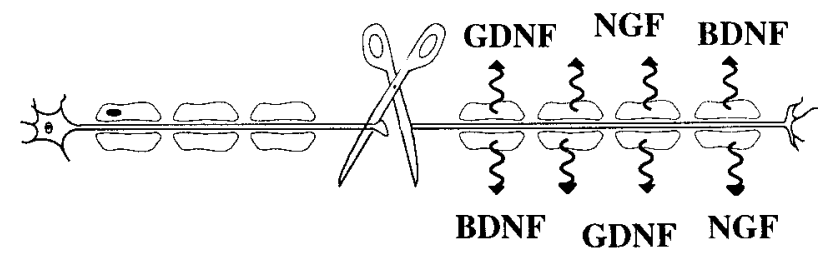

\section{Spinal Cord}

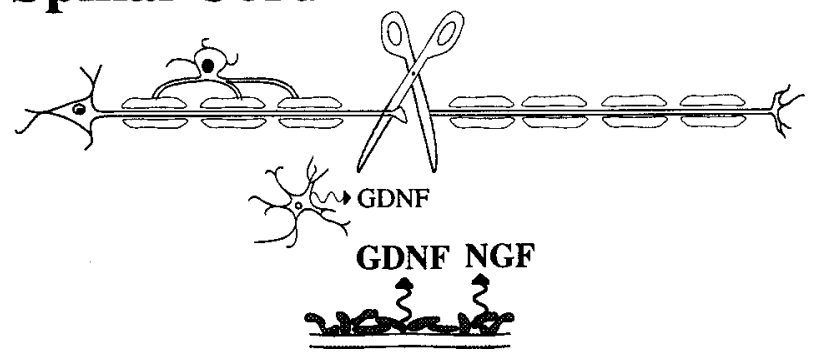

Figure 18. Schematic representation of differences in non-neuronal neurotrophic support between the PNS and the spinal cord after injury. The comparison is valid, for instance, for upper and lower motoneurons. Although the Schwann cells in the PNS increase their synthesis of NGF, BDNF, and GDNF (Johnson et al., 1988; Meyer et al., 1992; Funakoshi et al., 1993; Naveilhan et al., 1997; Trupp et al., 1997), the oligodendrocytes in the CNS do not. After SCI the short-lived sources of neurotrophic support are meningeal cells and astrocytes localized to the site of injury. In comparison with GDNF mRNA upregulation in injured nerve roots, the GDNF mRNA signals in astrocytes were only minor. Higher relative mRNA levels are indicated by larger letters.

spinal cord do not respond in a similar supportive way (Fig. 18). This demonstrates marked differences between the PNS and the spinal cord regarding neurotrophic support after injury and supports the idea that one reason for the lack of regeneration in the CNS may be insufficient trophic support.

Although no specific neurotrophic factor or neurotrophic factor receptor mRNA was found in oligodendrocytes, GDNF, truncated TrkB, and GFR $\alpha-1$ were detected in astrocytes. This suggests that astrocytes can be supportive of nerve fiber growth. Indeed, an association between reactive astrocytes and regenerating nerve fibers in the CNS white matter in vivo has been shown (Davies et al., 1997, 1999). Because no Trk receptors or p75 mRNAs could be detected in oligodendrocytes in vivo, the myelination-inducing effects of BDNF and NT3 shown previously (McTigue et al., 1998) on regenerating axons are likely to be mediated through another receptor or receptors or indirectly.

This study provides a detailed view of the distribution and regulation of $15 \mathrm{key}$ gene products belonging to the NGF and GDNF families, the corresponding receptors, as well as CNTF, in the normal and injured neonatal and adult spinal cord. Information about upregulations that occur in the injured cord as well as about factors and receptors that are unable to respond to injury should aid in the design of appropriate trophic factor combinations to test as neuroprotective/reparative treatments in SCI.

\section{REFERENCES}

Altar CA, DiStefano PS (1998) Neurotrophin trafficking by anterograde transport. Trends Neurosci 21:433-437.

Baloh R, Tansey M, Golden J, Creedon D, Heuckeroth R, Keck C, Zimonjic D, Popescu N, Johnson Jr E, Milbrandt J (1997) TrnR2, a 
novel receptor that mediates neurturin and GDNF signaling through Ret. Neuron 18:793-802.

Baloh RH, Enomoto H, Johnson Jr EM, Milbrandt J (2000) The GDNF family ligands and receptors: implications for neural development. Curr Opin Neurobiol 10:103-110.

Basso DM, Beattie MS, Bresnahan JC (1995) A sensitive and reliable locomotor rating scale for open field testing in rats. J Neurotrauma $12: 1-21$.

Bennett DL, Michael GJ, Ramachandran N, Munson JB, Averill S, Yan Q, McMahon SB, Priestley JV (1998) A distinct subgroup of small DRG cells express GDNF receptor components and GDNF is protective for these neurons after nerve injury. J Neurosci 18:3059-3072.

Bergman E, Kullberg S, Ming Y, Ulfhake B (1999) Upregulation of GFRalpha-1 and c-ret in primary sensory neurons and spinal motoneurons of aged rats. J Neurosci Res 57:153-165.

Bernstein DR, Stelzner DJ (1983) Plasticity of the corticospinal tract following midthoracic spinal injury in the postnatal rat. J Comp Neurol 221:382-400.

Bignami A, Ralston III HJ (1969) The cellular reaction to Wallerian degeneration in the central nervous system of the cat. Brain Res 13:444-461.

Blesch A, Uy HS, Grill RJ, Cheng JG, Patterson PH, Tuszynski MH (1999) Leukemia inhibitory factor augments neurotrophin expression and corticospinal axon growth after adult CNS injury. J Neurosci 19:3556-3566.

Bregman BS, Goldberger ME (1983) Infant lesion effect: III. Anatomical correlates of sparing and recovery of function after spinal cord damage in newborn and adult cats. Brain Res 285:137-154.

Brösamle C, Schwab ME (1997) Cells of origin, course, and termination patterns of the ventral, uncrossed component of the mature rat corticospinal tract. J Comp Neurol 386:293-303.

Casale EJ, Light AR, Rustioni A (1988) Direct projection of the corticospinal tract to the superficial laminae of the spinal cord in the rat. J Comp Neurol 278:275-286.

Chen MS, Huber AB, van der Haar ME, Frank M, Schnell L, Spillmann AA, Christ F, Schwab ME (2000) Nogo-A is a myelin-associated neurite outgrowth inhibitor and an antigen for monoclonal antibody IN-1. Nature 403:434-439.

Conner J, Lauterborn J, Yan Q, Gall C, Varon S (1997) Distribution of brain-derived neurotrophic factor (BDNF) protein and mRNA in the normal adult rat CNS: evidence for anterograde axonal transport. J Neurosci 17:2295-2313.

Cook RD, Wisniewski HM (1973) The role of oligodendroglia and astroglia in Wallerian degeneration of the optic nerve. Brain Res 61:191-206.

Curran T, Gordon MB, Rubino KL, Sambucetti LC (1987) Isolation and characterization of the c-fos (rat) cDNA and analysis of posttranslational modification in vitro. Oncogene 2:79-84.

Dagerlind Å, Friberg K, Bean A, Hökfelt T (1992) Sensitive mRNA detection using unfixed tissue: combined radioactive and nonradioactive in situ hybridization histochemistry. Histochemistry 98:39-49.

Davies AM, Lee KF, Jaenisch R (1993) p75-deficient trigeminal sensory neurons have an altered response to NGF but not to other neurotrophins. Neuron 11:565-574.

Davies SJ, Fitch MT, Memberg SP, Hall AK, Raisman G, Silver J (1997) Regeneration of adult axons in white matter tracts of the central nervous system. Nature 390:680-683.

Davies SJ, Goucher DR, Doller C, Silver J (1999) Robust regeneration of adult sensory axons in degenerating white matter of the adult rat spinal cord. J Neurosci 19:5810-5822.

Dechant G, Barde YA (1997) Signalling through the neurotrophin receptor p75NTR. Curr Opin Neurobiol 7:413-418.

DiStefano PS, Curtis R (1994) Receptor mediated retrograde axonal transport of neurotrophic factors is increased after peripheral nerve injury. Prog Brain Res 103:35-42.

Doster SK, Lozano AM, Aguayo AJ, Willard MB (1991) Expression of the growth-associated protein GAP-43 in adult rat retinal ganglion cells following axon injury. Neuron 6:635-647.

Eddleston M, Mucke L (1993) Molecular profile of reactive astrocytesimplications for their role in neurologic disease. Neuroscience 54:15-36.

Elkabes S, Dreyfus CF, Schaar DG, Black IB (1994) Embryonic sensory development: local expression of neurotrophin-3 and target expression of nerve growth factor. J Comp Neurol 341:204-213.

Ernfors P, Henschen A, Olson L, Persson H (1989) Expression of nerve growth factor receptor mRNA is developmentally regulated and increased after axotomy in rat spinal cord motoneurons. Neuron 2:1605-1613.

Ernfors P, Persson H (1991) Developmentally regulated expression of HDNF/NT-3 mRNA in rat spinal cord motoneurons and expression of BDNF mRNA in embryonic dorsal root ganglion. Eur $\mathrm{J}$ Neurosci 3:953-961.

Ernfors P, Merlio J, Persson H (1992) Cells expressing mRNA for neu- rotrophins and their receptors during embryonic rat development. Eur J Neurosci 4:1140-1158.

Faden AI, Lemke M, Simon RP, Noble LJ (1988) N-methyl-D-aspartate antagonist MK801 improves outcome following traumatic spinal cord injury in rats: behavioral, anatomic, and neurochemical studies. J Neurotrauma 5:33-45.

Feinstein DL, Weinmaster GA, Milner RJ (1992) Isolation of cDNA clones encoding rat glial fibrillary acidic protein: expression in astrocytes and in Schwann cells. J Neurosci Res 32:1-14.

Fournier AE, McKerracher L (1997) Expression of specific tubulin isotypes increases during regeneration of injured CNS neurons, but not after the application of brain-derived neurotrophic factor (BDNF). J Neurosci 17:4623-4632.

Frisén J, Verge VM, Cullheim S, Persson H, Fried K, Middlemas DS, Hunter T, Hökfelt T, Risling M (1992) Increased levels of trkB mRNA and trkB protein-like immunoreactivity in the injured rat and cat spinal cord. Proc Natl Acad Sci USA 89:11282-11286.

Frisén J, Verge VM, Fried K, Risling M, Persson H, Trotter J, Hökfelt T, Lindholm D (1993) Characterization of glial trkB receptors: differential response to injury in the central and peripheral nervous systems. Proc Natl Acad Sci USA 90:4971-4975.

Frisén J, Risling M, Korhonen L, Zirrgiebel U, Johansson CB, Cullheim S, Lindholm D (1998) Nerve growth factor induces process formation in meningeal cells: implications for scar formation in the injured CNS. J Neurosci 18:5714-5722.

Funakoshi H, Frisén J, Barbany G, Timmusk T, Zachrisson O, Verge VM, Persson H (1993) Differential expression of mRNAs for neurotrophins and their receptors after axotomy of the sciatic nerve. J Cell Biol 123:455-465.

Gall C, Isackson P (1989) Limbic seizures increase neuronal production of messenger RNA for nerve growth factor. Science 245:758-761.

Giehl KM, Tetzlaff W (1996) BDNF and NT-3, but not NGF, prevent axotomy-induced death of rat corticospinal neurons in vivo. Eur J Neurosci 8:1167-1175.

Golden JP, DeMaro JA, Osborne PA, Milbrandt J, Johnson Jr EM (1999) Expression of neurturin, GDNF, and GDNF family-receptor mRNA in the developing and mature mouse. Exp Neurol 158:504-528.

Gomez-Pinilla F, Tram H, Cotman CW, Nieto-Sampedro M (1989) Neuroprotective effect of MK-801 and U-50488H after contusive spinal cord injury. Exp Neurol 104:118-124.

Grill R, Murai K, Blesch A, Gage FH, Tuszynski MH (1997) Cellular delivery of neurotrophin-3 promotes corticospinal axonal growth and partial functional recovery after spinal cord injury. J Neurosci 17:5560-5572.

Gruner JA (1992) A monitored contusion model of spinal cord injury in the rat. J Neurotrauma 9:123-128.

Hayashi M, Ueyama T, Nemoto K, Tamaki T, Senba E (2000) Sequential mRNA expression for immediate early genes, cytokines, and neurotrophins in spinal cord injury. J Neurotrauma 17:203-218.

Henderson C, Phillips H, Pollick R, Davies A, Lemeulle C, Armanini M, Simmons L, Moffet B, Vandlen R (1994) GDNF: a potent survival factor for motoneurons present in peripheral nerve and muscle. Science 266:1062-1064.

Hoke A, Silver J (1996) Proteoglycans and other repulsive molecules in glial boundaries during development and regeneration of the nervous system. Prog Brain Res 108:149-163.

Horger BA, Nishimura MC, Armanini MP, Wang LC, Poulsen KT, Rosenblad C, Kirik D, Moffat B, Simmons L, Johnson Jr E, Milbrandt J, Rosenthal A, Björklund A, Vandlen RA, Hynes MA, Phillips HS (1998) Neurturin exerts potent actions on survival and function of midbrain dopaminergic neurons. J Neurosci 18:4929-4937.

Houweling DA, Lankhorst AJ, Gispen WH, Bar PR, Joosten EA (1998) Collagen containing neurotrophin-3 (NT-3) attracts regrowing injured corticospinal axons in the adult rat spinal cord and promotes partial functional recovery. Exp Neurol 153:49-59.

Hugon J, Vallat JM, Spencer PS, Leboutet MJ, Barthe D (1989) Kainic acid induces early and delayed degenerative neuronal changes in rat spinal cord. Neurosci Lett 104:258-262.

Ibáñez CF (1998) Emerging themes in structural biology of neurotrophic factors. Trends Neurosci 21:438-444.

Indo Y, Mardy S, Tsuruta M, Karim MA, Matsuda I (1997) Structure and organization of the human TRKA gene encoding a high affinity receptor for nerve growth factor. Jpn J Hum Genet 42:343-351.

Ip NY, Ibáñez CF, Nye SH, McClain J, Jones PF, Gies DR, Belluscio L, Le Beau MM, Espinosa R, Squinto SP, Persson H, Yancopoulos G (1992) Mammalian neurotrophin-4: structure, chromosomal localization, tissue distribution, and receptor specificity. Proc Natl Acad Sci USA 89:3060-3064

Iwamoto T, Taniguchi M, Asai N, Ohkusu K, Nakashima I, Takahashi M (1993) cDNA cloning of mouse ret proto-oncogene and its sequence similarity to the cadherin superfamily. Oncogene 8:1087-1091.

Johnson EM Jr, Taniuchi M, DiStefano PS (1988) Expression and possible function of nerve growth factor receptors on Schwann cells. Trends Neurosci 11:299-304.

Klein R, Martin-Zanca D, Barbacid M, Parada LF (1990) Expression of 
the tyrosine kinase receptor gene trkB is confined to the murine embryonic and adult nervous system. Development 109:845-850.

Kobayashi NR, Fan DP, Giehl KM, Bedard AM, Wiegand SJ, Tetzlaff W (1997) BDNF and NT-4/5 prevent atrophy of rat rubrospinal neurons after cervical axotomy, stimulate GAP-43 and T $\alpha 1$-tubulin mRNA expression, and promote axonal regeneration. J Neurosci 17:9583-9595.

Kokaia Z, Airaksinen MS, Nanobashvili A, Larsson E, Kujamaki E, Lindvall O, Saarma M (1999) GDNF family ligands and receptors are differentially regulated after brain insults in the rat. Eur J Neurosci 11:1202-1216.

Korsching S, Thoenen H (1985) Nerve growth factor supply for sensory neurons: site of origin and competition with the sympathetic nervous system. Neurosci Lett 54:201-205.

Kotzbauer P, Lampe P, Heuckeroth R, Golden J, Creedon D, Johnson Jr E, Milbrandt J (1996) Neurturin, a relative of glial-cell-line-derived neurotrophic factor. Nature 384:467-470.

Leibrock J, Lottspeich F, Hohn A, Hofer M, Hengerer B, Masiakowski P, Thoenen H, Barde YA (1989) Molecular cloning and expression of brain-derived neurotrophic factor. Nature 341:149-152.

Leitner ML, Molliver DC, Osborne PA, Vejsada R, Golden JP, Lampe PA, Kato AC, Milbrandt J, Johnson Jr EM (1999) Analysis of the retrograde transport of glial cell line-derived neurotrophic factor (GDNF), neurturin, and persephin suggests that in vivo signaling for the GDNF family is GFR $\alpha$ coreceptor-specific. J Neurosci 19:9322-9331.

Lin L-F, Doherty D, Lile J, Bektesh S, Collins F (1993) GDNF: a glial cell line-derived neurotrophic factor for midbrain dopaminergic neurons. Science 260:1130-1132.

Lindsay RM (1994) Neurotrophins and receptors. Prog Brain Res 103:3-14.

Liu Y, Kim D, Himes BT, Chow SY, Schallert T, Murray M, Tessler A, Fischer I (1999) Transplants of fibroblasts genetically modified to express BDNF promote regeneration of adult rat rubrospinal axons and recovery of forelimb function. J Neurosci 19:4370-4387.

Lowrie MB, Vrbova G (1992) Dependence of postnatal motoneurones on their targets: review and hypothesis. Trends Neurosci 15:80-84.

Maisonpierre P, Belluscio L, Squinto S, Ip N, Furth M, Lindsay R, Yancopoulos G (1990) Neurotrophin-3: a neurotrophic factor related to NGF and BDNF. Science 247:1446-1451.

Martin LJ, Blackstone CD, Levey AI, Huganir RL, Price DL (1993) AMPA glutamate receptor subunits are differentially distributed in rat brain. Neuroscience 53:327-358.

Martin-Zanca D, Hughes SH, Barbacid M (1986) A human oncogene formed by the fusion of truncated tropomyosin and protein tyrosine kinase sequences. Nature 319:743-748.

McAllister AK, Katz LC, Lo DC (1999) Neurotrophins and synaptic plasticity. Annu Rev Neurosci 22:295-318.

McBride RL, Feringa ER, Garver MK, Williams Jr JK (1989) Prelabeled red nucleus and sensorimotor cortex neurons of the rat survive 10 and 20 weeks after spinal cord transection. J Neuropathol Exp Neurol 48:568-576.

McTigue DM, Horner PJ, Stokes BT, Gage FH (1998) Neurotrophin-3 and brain-derived neurotrophic factor induce oligodendrocyte proliferation and myelination of regenerating axons in the contused adult rat spinal cord. J Neurosci 18:5354-5365.

Menei P, Montero-Menei C, Whittemore SR, Bunge RP, Bunge MB (1998) Schwann cells genetically modified to secrete human BDNF promote enhanced axonal regrowth across transected adult rat spinal cord. Eur J Neurosci 10:607-621.

Merline M, Kalil K (1990) Cell death of corticospinal neurons is induced by axotomy before but not after innervation of spinal targets. J Comp Neurol 296:506-516.

Merlio JP, Ernfors P, Jaber M, Persson H (1992) Molecular cloning of rat trkC and distribution of cells expressing messenger RNAs for members of the trk family in the rat central nervous system. Neuroscience 51:513-532.

Meyer M, Matsuoka I, Wetmore C, Olson L, Thoenen H (1992) Enhanced synthesis of brain-derived neurotrophic factor in the lesioned peripheral nerve: different mechanisms are responsible for the regulation of BDNF and NGF mRNA. J Cell Biol 119:45-54.

Middlemas DS, Lindberg RA, Hunter T (1991) trkB, a neural receptor protein-tyrosine kinase: evidence for a full-length and two truncated receptors. Mol Cell Biol 11:143-153.

Milbrandt J, de Sauvage F, Fahrner T, Baloh R, Leitner M, Tansey M, Lampe P, Heuckeroth R, Kotzbauer P, Simburger K, Golden J, Davies J, Vejsada R, Kato A, Hynes M, Sherman D, Nishimura M, Wang L, Vandlen R, Moffat B, Klein R, Poulsen K, Gray C, Garces A, Johnson EJ (1998) Persephin, a novel neurotrophic factor related to GDNF and neurturin. Neuron 20:245-253.

Naveilhan P, ElShamy W, Ernfors P (1997) Differential regulation of mRNAs for GDNF and its receptors Ret and GDNFR alpha after sciatic nerve lesion in the mouse. Eur J Neurosci 9:1450-1460.

Nosrat C, Olson L (1995) Brain-derived neurotrophic factor mRNA is expressed in the developing taste bud-bearing tongue papillae of rat. J Comp Neurol 360:698-704.
Nosrat C, Tomac A, Lindqvist E, Lindskog S, Humpel C, Strömberg I, Ebendal T, Hoffer B, Olson L (1996) Cellular expression of GDNF mRNA suggests multiple functions inside and outside the nervous system. Cell Tissue Res 286:191-207.

Nosrat C, Tomac A, Hoffer B, Olson L (1997a) Cellular and developmental patterns of expression of Ret and GDNFR- $\alpha$ mRNA. Exp Brain Res 115:410-422.

Nosrat CA, Fried K, Lindskog S, Olson L (1997b) Cellular expression of neurotrophin mRNAs during tooth development. Cell Tissue Res 290:569-580.

Novikova L, Novikov L, Kellerth JO (1996) Brain-derived neurotrophic factor reduces necrotic zone and supports neuronal survival after spinal cord hemisection in adult rats. Neurosci Lett 220:203-206.

Park CM, Clegg KE, Harvey-Clark CJ, Hollenberg MJ (1992) Improved techniques for successful neonatal rat surgery. Lab Anim Sci 42:508-513.

Paxinos G, Watson C (1986) The rat brain in stereotaxic coordinates, Ed 2. North Ryde, Australia: Academic.

Pisharodi M, Nauta HJ (1985) An animal model for neuron-specific spinal cord lesions by the microinjection of $N$-methylaspartate, kainic acid, and quisqualic acid. Appl Neurophysiol 48:226-233.

Radeke MJ, Misko TP, Hsu C, Herzenberg LA, Shooter EM (1987) Gene transfer and molecular cloning of the rat nerve growth factor receptor. Nature 325:593-597.

Reynolds ME, Brunello N, Mocchetti I, Wrathall JR (1991) Localization of nerve growth factor receptor mRNA in contused rat spinal cord by in situ hybridization. Brain Res 559:149-153.

Risling M, Fried K, Lindå H, Cullheim S, Meier M (1992) Changes in nerve growth factor receptor-like immunoreactivity in the spinal cord after ventral funiculus lesion in adult cats. J Neurocytol 21:79-93.

Rosenblad C, Kirik D, Devaux B, Moffat B, Phillips HS, Björklund A (1999) Protection and regeneration of nigral dopaminergic neurons by neurturin or GDNF in a partial lesion model of Parkinson's disease after administration into the striatum or the lateral ventricle. Eur J Neurosci 11:1554-1566.

Rosenblad C, Gronborg M, Hansen C, Blom N, Meyer M, Johansen J, Dago L, Kirik D, Patel UA, Lundberg C, Trono D, Björklund A, Johansen TE (2000) In vivo protection of nigral dopamine neurons by lentiviral gene transfer of the novel GDNF-family member neublastin/ artemin. Mol Cell Neurosci 15:199-214.

Rydén M, Hempstead B, Ibáñez CF (1997) Differential modulation of neuron survival during development by nerve growth factor binding to the p75 neurotrophin receptor. J Biol Chem 272:16322-16328.

Sanicola M, Hession C, Worley D, Carmillo P, Ehrenfels C, Walus L, Robinson S, Jaworski G, Wei H, Tizard R, Whitty A, Pepinsky R, Cate R (1997) Glial cell line-derived neurotrophic factor-dependent RET activation can be mediated by two different cell-surface accessory proteins. Proc Natl Acad Sci USA 94:6238-6243.

Sato K, Kiyama H, Tohyama M (1993) The differential expression patterns of messenger RNAs encoding non- $N$-methyl-D-aspartate glutamate receptor subunits $(\mathrm{GluR} 1-4)$ in the rat brain. Neuroscience 52:515-539.

Scarisbrick IA, Isackson PJ, Windebank AJ (1999) Differential expression of brain-derived neurotrophic factor, neurotrophin-3, and neurotrophin-4/5 in the adult rat spinal cord: regulation by the glutamate receptor agonist kainic acid. J Neurosci 19:7757-7769.

Schmidt-Kastner R, Tomac A, Hoffer B, Bektesh S, Rosenzweig B, Olson L (1994) Glial cell-line derived neurotrophic factor (GDNF) mRNA upregulation in striatum and cortical areas after pilocarpine-induced status epilepticus in rats. Brain Res Mol Brain Res 26:325-330.

Schnell L (1994) Neurotrophine-3 enhances sprouting of corticospinal tract during development and after spinal cord lesion. Nature $367: 170-173$

Skene JH (1989) Axonal growth-associated proteins. Annu Rev Neurosci $12: 127-156$.

Sperk G, Lassmann H, Baran H, Seitelberger F, Hornykiewicz O (1985) Kainic acid-induced seizures: dose-relationship of behavioural, neurochemical and histopathological changes. Brain Res 338:289-295.

Terashima T (1995) Anatomy, development and lesion-induced plasticity of rodent corticospinal tract. Neurosci Res 22:139-161.

Tetzlaff W, Kobayashi NR, Giehl KM, Tsui BJ, Cassar SL, Bedard AM (1994) Response of rubrospinal and corticospinal neurons to injury and neurotrophins. Prog Brain Res 103:271-286.

Thoenen H (1991) The changing scene of neurotrophic factors. Trends Neurosci 14:165-170.

Timmusk T, Belluardo N, Metsis M, Persson H (1993) Widespread and developmentally regulated expression of neurotrophin-4 mRNA in rat brain and peripheral tissues. Eur J Neurosci 5:605-613.

Tomac A, Lindqvist E, Lin LF, Ögren SO, Young D, Hoffer BJ, Olson L (1995) Protection and repair of the nigrostriatal dopaminergic system by GDNF in vivo. Nature 373:335-339.

Treanor J, Goodman L, Desauvage F, Stone D, Poulsen K, Beck C, Gray C, Armanini M, Pollock R, Hefti F, Phillips H, Goddard A, Moore M, Bujbello A, Davies A, Asai N, Takahashi M, Vandlen R, Henderson C, 
Rosenthal A (1996) Characterization of a multicomponent receptor for GDNF. Nature 382:80-83.

Trupp M, Arenas E, Fainzilber M, Nilsson AS, Sieber BA, Grigoriou M, Kilkenny C, Salazar-Grueso E, Pachnis V, Arumae U (1996) Functional receptor for GDNF encoded by the c-ret proto-oncogene. Nature 381:785-789.

Trupp M, Belluardo N, Funakoshi H, Ibáñez C (1997) Complementary and overlapping expression of glial cell line-derived neurotrophic factor (GDNF), c-ret proto-oncogene, and GDNF receptor- $\alpha$ indicates multiple mechanisms of trophic actions in the adult rat CNS. J Neurosci 17:3554-3567.

Trupp M, Raynoschek C, Belluardo N, Ibáñez CF (1998) Multiple GPIanchored receptors control GDNF-dependent and independent activation of the c-ret receptor tyrosine kinase. Mol Cell Neurosci 11:47-63.

Trupp M, Scott R, Whittemore SR, Ibáñez CF (1999) Ret-dependent and -independent mechanisms of glial cell line-derived neurotrophic factor signaling in neuronal cells. J Biol Chem 274:20885-20894.

Tuszynski MH, Gabriel K, Gage FH, Suhr S, Meyer S, Rosetti A (1996) Nerve growth factor delivery by gene transfer induces differential outgrowth of sensory, motor, and noradrenergic neurites after adult spinal cord injury. Exp Neurol 137:157-173.

von Euler M, Seiger A, Holmberg L, Sundström E (1994) NBQX, a competitive non-NMDA receptor antagonist, reduces degeneration due to focal spinal cord ischemia. Exp Neurol 129:163-168.

Wetmore C, Olson L (1993) Expression and regulation of neurotrophins and their receptors in hippocampal systems. Hippocampus 3:171-181.
Wetmore C, Olson L (1995) Neuronal and nonneuronal expression of neurotrophins and their receptors in sensory and sympathetic ganglia suggest new intercellular trophic interactions. J Comp Neurol 353:143-159.

Wetmore C, Ernfors P, Persson H, Olson L (1990) Localization of brain-derived neurotrophic factor mRNA to neurons in the brain by in situ hybridization. Exp Neurol 109:141-152.

Whittemore SR, Friedman PL, Larhammar D, Persson H, GonzalezCarvajal M, Holets VR (1988) Rat $\beta$-nerve growth factor sequence and site of synthesis in the adult hippocampus. J Neurosci Res 20:403-410.

Widenfalk J, Nosrat C, Tomac A, Westphal H, Hoffer B, Olson L (1997) Neurturin and GDNFR- $\beta$, novel proteins related to GDNF and GDNFR- $\alpha$ with specific cellular patterns of expression suggesting roles in the developing and adult nervous system and in peripheral organs. J Neurosci 17:8506-8519.

Widenfalk J, Widmer HR, Spenger C (1999a) GDNF, RET and GFRalpha-1-3 mRNA expression in the developing human spinal cord and ganglia. NeuroReport 10:1433-1439.

Widenfalk J, Olson L, Thoren P (1999b) Deprived of habitual running, rats downregulate BDNF and TrkB messages in the brain. Neurosci Res 34:125-132.

Wrathall JR, Choiniere D, Teng YD (1994) Dose-dependent reduction of tissue loss and functional impairment after spinal cord trauma with the AMPA/kainate antagonist NBQX. J Neurosci 14:6598-6607. 